\title{
Control of Food Intake and Energy Expenditure by Nos1 Neurons of the Paraventricular Hypothalamus
}

\author{
Amy K. Sutton, ${ }^{1}$ Hongjuan Pei, ${ }^{2}$ Korri H. Burnett, ${ }^{2}$ Martin G. Myers Jr., ${ }^{1,3}$ Christopher J. Rhodes, ${ }^{4}$ and David P. Olson ${ }^{2}$ \\ ${ }^{1}$ Department of Molecular \& Integrative Physiology, ${ }^{2}$ Division of Division of Pediatric Endocrinology, Department of Pediatrics \& Communicable Diseases, \\ and ${ }^{3}$ Department of Internal Medicine, University of Michigan Health System, Ann Arbor, Michigan 48109, and ${ }^{4}$ Department of Internal Medicine, \\ University of Chicago, Chicago, Illinois 60637
}

\begin{abstract}
The paraventricular nucleus of the hypothalamus (PVH) contains a heterogeneous cluster of Sim1-expressing cell types that comprise a major autonomic output nucleus and play critical roles in the control of food intake and energy homeostasis. The roles of specific PVH neuronal subtypes in energy balance have yet to be defined, however. The PVH contains nitric oxide synthase-1 (Nos1)-expressing $\left(\mathrm{Nos}_{1}^{\mathrm{PVH}}\right)$ neurons of unknown function; these represent a subset of the larger population of Sim1-expressing PVH (Sim1 ${ }^{\mathrm{PVH}}$ ) neurons. To determine the role of Nos ${ }^{\mathrm{PVH}}$ neurons in energy balance, we used Cre-dependent viral vectors to both map their efferent projections and test their functional output in mice. Here we show that Nos $1^{\mathrm{PVH}}$ neurons project to hindbrain and spinal cord regions important for food intake and energy expenditure control. Moreover, pharmacogenetic activation of Nos $1^{\mathrm{PVH}}$ neurons suppresses feeding to a similar extent as Sim1 ${ }^{\mathrm{PVH}}$ neurons, and increases energy expenditure and activity. Furthermore, we found that oxytocin-expressing PVH neurons $\left(\mathrm{OXT}^{\mathrm{PVH}}\right)$ are a subset of Nos ${ }^{\mathrm{PVH}}$ neurons. $\mathrm{OXT}^{\mathrm{PVH}}$ cells project to preganglionic, sympathetic neurons in the thoracic spinal cord and increase energy expenditure upon activation, though not to the same extent as $\operatorname{Nos}^{\mathrm{PVH}}$ neurons; their activation fails to alter feeding, however. Thus, Nos $1^{\mathrm{PVH}}$ neurons promote negative energy balance through changes in feeding and energy expenditure, whereas $\mathrm{OXT}^{\mathrm{PVH}}$ neurons regulate energy expenditure alone, suggesting a crucial role for non-OXT Nos $1^{\mathrm{PVH}}$ neurons in feeding regulation.
\end{abstract}

Key words: body weight; energy balance; hypothalamus; oxygen consumption; oxytocin; satiety

\section{Introduction}

The paraventricular nucleus of the hypothalamus $(\mathrm{PVH})$ is the major autonomic output area of the hypothalamus and is critical for energy homeostasis. Loss of one copy of single-minded 1 (Sim1), a key transcription factor regulating PVH development, disrupts PVH maturation and function, resulting in hyperphagic obesity with associated glucose dysregulation in mammals (Michaud et al., 1998; Holder et al., 2000). Similar metabolic derangements also result from electrolytic destruction of the PVH (Gold, 1973; Sims and Lorden, 1986). In addition, the PVH serves as an important regulatory center for peptidergic signals and

Received Jan. 17, 2014; revised Sept. 25, 2014; accepted 0ct. 5, 2014.

Author contributions: A.K.S. and D.P.O. designed research; A.K.S., H.P., and K.H.B. performed research; M.G.M. and C.J.R. contributed unpublished reagents/analytic tools; A.K.S. and D.P.O. analyzed data; A.K.S. and D.P.O. wrote the paper.

Core support (Animal Phenotyping) was provided by the University of Michigan Animal Phenotyping Core. This work was supported by the National Institutes of Health (Grants F31 NS082027-01 and T32 GM 8322-22 to A.K.S.), the Michigan Diabetes Research and Training Center Pilot and Feasibility Award (NIH Grant5P60 DK20572 to D.P.0.), and NIH P30 Grants DK089503 and DK020572 to the Animal Phenotyping Core. We thank the members of the Myers laboratory for helpful discussions and technical support; and Dr. Michael Scott and the Scott laboratory (University of Virginia, Charlottesville, VA) for training in targeted stereotaxic injections into the nucleus of the solitary tract. We also thank Dr. Sebastian Parlee, Dr. Hiroyuki Mori, and the MacDougald Laboratory (University of Michigan) for their advice and assistance with Western blots.

The authors declare no competing financial interests.

Correspondence should be addressed to Dr. David P. Olson, Department of Pediatrics, Division of Pediatric Endocrinology, University of Michigan Health System, D1205 MPB/SPC 5718, Ann Arbor, MI 48109. E-mail: dpolson@med.umich.edu.

DOI:10.1523/JNEUROSCI.0226-14.2014

Copyright $\odot 2014$ the authors $\quad 0270-6474 / 14 / 3415306-13 \$ 15.00 / 0$ physiologic parameters known to modulate food intake, including leptin, melanocortins, and dehydration (Cowley et al., 1999; McKinley and Johnson, 2004). Indeed, the melanocortin pathway is essential for energy balance in mammals and is directly linked to PVH function. Leptin-responsive neurons in the arcuate nucleus project to the $\mathrm{PVH}$, a site of dense melanocortin receptor expression, and release melanocortin agonists and antagonists/inverse agonists to modulate PVH function (Cowley et al., 1999; Kishi et al., 2003). Consistent with its role in feeding, the $\mathrm{PVH}$ sends dense projections to hindbrain regions such as the nucleus of the solitary tract (NTS) and parabrachial nucleus (PBN) to modulate feeding behaviors (Sawchenko and Swanson, 1982; Fulwiler and Saper, 1985; Blevins et al., 2004). Although $\mathrm{PVH}$ functions are understood in broad terms, the specific cell types within this heterogeneous structure that regulate feeding are not fully defined.

In addition to modulating feeding, a variety of data suggest that PVH neurons control energy expenditure. For example, infusion of the melanocortin receptor agonist MTII into the PVH increases energy expenditure (Cowley et al., 1999), while ablation of Sim1 neurons throughout the CNS decreases the metabolic rate (Xi et al., 2012). Furthermore, polysynaptic retrograde tracing links thermogenic brown adipose tissue (BAT) to the PVH through the sympathetic nervous system via cholinergic [choline acetyltransferase (ChAT)] preganglionic neurons in the intermediolateral column of the thoracic spinal cord (ChAT ${ }^{\mathrm{IML}}$; Bamshad et al., 1999). Similar to the PVH cells that control feeding, 
the neurochemical identity of the PVH neurons regulating energy expenditure via the sympathetic nervous system (SNS) has yet to be established.

Given the role of the PVH in energy balance, we sought to identify subsets of Sim1-expressing PVH ( $\mathrm{Sim}^{\mathrm{PVH}}$ ) neurons that contribute to energy homeostasis and reveal their roles in food intake or energy expenditure. We discovered that PVH containing nitric oxide synthase-1 (Nos1)-expressing (Nos1 $\left.{ }^{\mathrm{PVH}}\right)$ neurons are a subset of $\operatorname{Sim} 1^{\mathrm{PVH}}$ neurons and send dense projections to hindbrain regions important for feeding control and to the upper thoracic spinal cord that regulates sympathetic output. Moreover, Nos1 ${ }^{\mathrm{PVH}}$ neuron activation regulates both feeding and energy expenditure, indicating the critical importance of $\mathrm{Nos}^{\mathrm{PVH}}$ neurons in $\mathrm{PVH}$ regulated energy balance. In addition, oxytocin-expressing $\mathrm{PVH}$ neurons $\left(\mathrm{OXT}^{\mathrm{PVH}}\right)$ neurons represent a subset of Nos $1^{\mathrm{PVH}}$ neurons that project to and modulate $\mathrm{ChAT}^{\mathrm{IML}}$ neurons, yet make only a small contribution to energy balance. These studies demonstrate discrete roles for Nos $1^{\mathrm{PVH}}$ and $\mathrm{OXT}^{\mathrm{PVH}}$ neurons in energy balance, and position these neurons anatomically and functionally in the neural circuitry of energy balance.

\section{Materials and Methods}

Experimental animals. Oxytocin-ires-Cre (OXT-iCre), Nos1-ires-Cre (Nos1-iCre), and Sim1-Cre mice were generated as described previously (Balthasar et al., 2005; Leshan et al., 2012; Wu et al., 2012). Adult male mice (8-12 weeks old) were used for all studies. OXT-iCre, Nos1-iCre, or Sim1-iCre mice were bred to a Cre-dependent GFP reporter line (Bergner et al., 2014) to fluorescently label Cre-expressing PVH subpopulations. All animals were bred and housed within our colony according to guidelines approved by the University of Michigan Committee on the Care and Use of Animals. Unless otherwise noted, mice were provided ad libitum access to food and water.

Stereotaxic injections. OXT-iCre, Nos1-iCre, Sim1-Cre, and nontransgenic [wild-type (WT)] mice were given presurgical analgesia and anesthetized with isoflurane. Mice were placed in a digital stereotaxic frame (Model 1900, Kopf Instruments), and the skull was exposed. Intracranial injection coordinates were determined from bregma using the stereotaxic atlas of Paxinos and Franklin (2001). Viral injections were performed using a pressurized picospritzer system coupled to a pulled glass micropipette [coordinates from bregma: anteroposterior, -0.500 ; mediolateral, \pm 0.220 ; dorsoventral $(\mathrm{D} / \mathrm{V}),-4.800]$. For tract-tracing experiments, $50-150 \mathrm{nl}$ of the adenoviral synatophysin-mCherry terminal tracer (Ad-iN/syn-mCherry; Opland et al., 2013) was unilaterally injected into Sim1-Cre, Nos1-iCre, or OXT-iCre mice. Additionally, stereotaxic injection of Red Retrobeads (RRs; Lumafluor) was performed in the NTS of Sim1-Cre and Nos1-iCre mice with a Cre-dependent GFP reporter (lox-GFP). Control mice also received unilateral injection of RRs to determine PVH-NTS connections using OXT peptide staining. For NTS injections, mice were anesthetized and placed in the digital stereotax. The fourth ventricle was identified and used as a geographic landmark to determine the site of injection. A glass micropipette was lowered into the site $(\mathrm{D} / \mathrm{V},-0.630)$ and $\sim 25 \mathrm{nl}$ of RRs was injected. For functional analysis of $\mathrm{PVH}$ neurons, bilateral $\mathrm{PVH}$ injections of AAVhM3Dq-mCherry (AAV-hM3Dq, purchased from the University of North Carolina Vector Core, Chapel Hill, NC) were performed in Sim1Cre ( $50 \mathrm{nl} /$ side), Nos1-iCre ( $50 \mathrm{nl} /$ side), and OXT-iCre ( $75 \mathrm{nl} /$ side) mice. To control for viral transduction, nontransgenic (WT) mice also received bilateral injections of AAV-hM3Dq ( $75 \mathrm{nl} /$ side). Mice injected with the Ad-iN/syn-mCherry tracer were individually housed for $5 \mathrm{~d}$ following injection to allow for viral transduction and protein transport before perfusion, whereas mice injected with RRs were perfused after $7 \mathrm{~d}$ following injections. Mice injected with AAV-hM3Dq were allowed to recover for $7 \mathrm{~d}$ following surgery before further experiments were performed.

Food intake measurements. Following recovery, Nos1-iCre, OXT-iCre, Sim1-Cre, and WT mice with bilateral PVH AAV-hM3Dq injections were given PBS (intraperitoneally) for 3 consecutive days to allow for injection acclimatization. Before assessment, mice were fasted during the light cycle (9:00 A.M. to 6:00 P.M.) and had ad libitum access to water. Mice were then injected with vehicle [10\% (2-hydroxypropyl)- $\beta$-cyclodextrin; catalog \#C0926, Sigma) at the onset of feeding (6:00 P.M.) and food intake was measured at 2,4 , and $16 \mathrm{~h}$ (overnight) postinjection. The following day, mice were injected with clozapine- $\mathrm{N}$-oxide (CNO) at the onset of feeding $(0.3 \mathrm{mg} / \mathrm{kg}$ in $10 \% \beta$-cyclodextrin $)$, and food intake was measured at 2, 4, and $16 \mathrm{~h}$ following injection.

Energy expenditure measurements. Energy expenditure was measured using the Comprehensive Laboratory Monitoring System (CLAMS, Columbus Instruments) in the University of Michigan Small Animal Phenotyping Core to obtain multiparameter analysis, including open circuit calorimetry and activity via optical beam breaks. AAV-hM3Dq-injected mice were acclimatized to the sealed chambers for $2 \mathrm{~d}$ with free access to food and water. The experimentation room had $12 \mathrm{~h}$ dark/light cycles (6:00 P.M. to 6:00 A.M.), and the temperature was maintained at 20$23^{\circ} \mathrm{C}$. On experimental days (Day 3 and Day 4), food was removed at 9:00 A.M., and vehicle (Day 3) or CNO (Day $4,0.3 \mathrm{mg} / \mathrm{kg}$ ) was injected at 11:00 A.M. Food was then replaced at the onset of the dark cycle (6:00 P.M.). Although measurements [oxygen consumption $\left(\mathrm{VO}_{2}\right)$, carbon dioxide production, and spontaneous motor activity] were performed throughout the duration of the experiment, the data shown are the averaged $\mathrm{VO}_{2}$ or activity over the $4 \mathrm{~h}$ following injection of vehicle or $\mathrm{CNO}$.

Intrascapular temperature measurements. The University of Michigan Small Animal Phenotyping Core placed temperature transponders (IPTT-300 model with corresponding DAS-7007R reader, Bio Medic Data Systems) in the intrascapular subcutaneous tissue directly above brown adipose tissue under isoflurane anesthesia. Mice were allowed to recover for $14 \mathrm{~d}$ before testing. On the day of testing, food was removed from the cages at 9:00 A.M. Two hours later, mice with PVH-directed $\mathrm{AAV}-\mathrm{hM} 3 \mathrm{Dq}$ injections were injected with vehicle or $\mathrm{CNO}$, and temperatures were recorded before injection and at 15, 30, 60, and $120 \mathrm{~min}$ following injection.

Perfusion and immunohistochemistry. For tract-tracing experiments, mice were perfused $5 \mathrm{~d}$ (Ad-iN/syn-mCherry) or $7 \mathrm{~d}$ (RRs) after intracranial injection. At the end of the neuronal activation studies, mice with bilateral AAV-hM3Dq injections were treated with either vehicle or $\mathrm{CNO}$ and perfused 90 min later, as described previously (Münzberg et al., 2007). Briefly, mice were deeply anesthetized with an overdose of pentobarbital $(150 \mathrm{mg} / \mathrm{kg}$, i.p.) and transcardially perfused with sterile PBS followed by $10 \%$ neutral buffered formalin or $4 \%$ paraformaldehyde (for perfusions with spinal cord removal). Brains and spinal cords were removed, post-fixed, and dehydrated in 30\% sucrose before sectioning into $30 \mu \mathrm{m}$ slices on a freezing microtome (Leica). Coronal brain sections were collected in four representative sections, whereas longitudinal thoracic spinal cord sections were collected in three representative sections and stored at $-20^{\circ} \mathrm{C}$. For Fos immunohistochemistry (IHC), freefloating brain and spinal cord sections were pretreated with $30 \% \mathrm{H}_{2} \mathrm{O}_{2}$ to remove endogenous peroxidase activity, and then were blocked with normal goat or donkey serum and incubated in primary antibody overnight (rabbit anti-cFos 1:10,000; PC38, Calbiochem). Detection of primary antibody was performed by the avidin-biotin/diaminobenzidine (DAB) method (Biotin-SP-conjugated Donkey Anti-Rabbit, 1:200, Jackson ImmunoResearch; ABC kit, Vector Laboratories; DAB reagents, Sigma). hM3Dq and ChAT were detected using primary antibodies against red fluorescent protein (RFP; rat 1:2000, Allele Biotechnology) and ChAT (spinal cords only; goat, 1:500; AB144P, Millipore), respectively, followed by secondary immunofluorescence detection with donkey anti-rat-Alexa Fluor 568 or donkey anti-goat-Alexa Fluor 488 (1:200, Invitrogen). For PVH colocalization experiments, IHC immunostaining was performed using primary antibodies for GFP (rabbit, 1:20,000, Invitrogen A6455), nNOS1 (sheep, 1:2500; Herbison et al., 1996; provided by Dr. Vincent Prevot, Inserm, Lille, France), or oxytocin (rabbit, 1:2500; catalog \#T-4084, Peninsula Laboratories). For tract-tracing experiments, immunostaining was performed using primary antibodies for RFP, GFP, or oxytocin.

Immunoblotting of BAT UCP1 protein. Sim1-Cre, OXT-iCre, and WT mice with bilateral PVH AAV-hM3Dq injections were given either vehicle or $\mathrm{CNO}$ and $90 \mathrm{~min}$ later mice were anesthetized with pentobarbital, and BAT was removed, frozen on dry ice, and stored at $-80^{\circ} \mathrm{C}$. Tissue 

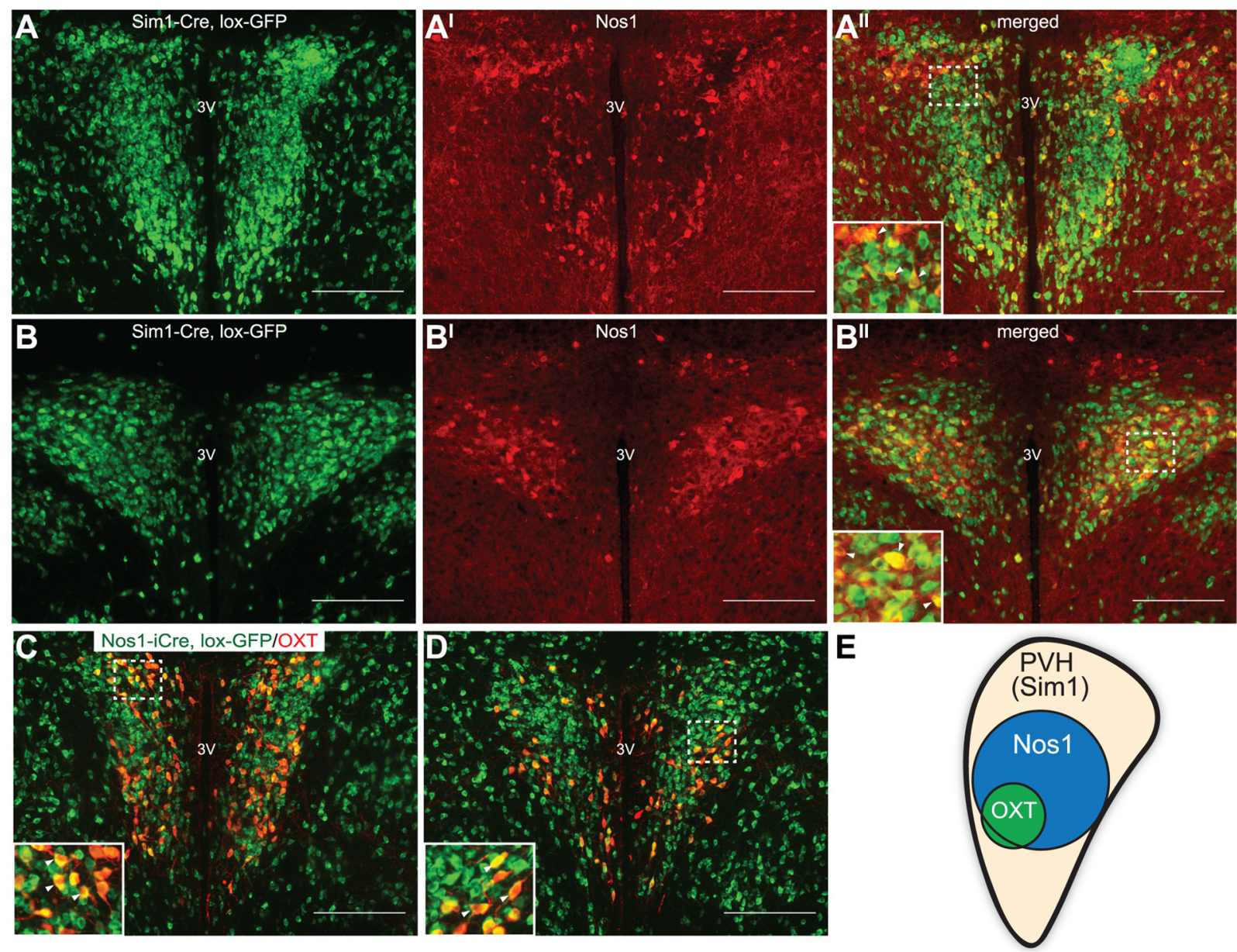

Figure 1. Neuronal Nos 1 marks a subset of PVH neurons. $A, B$, IHC for NOS1 peptide (red) in the PVH of Sim 1-Cre, lox-GFP reporter mice (lox-GFP, green) identifies Nos $1^{\text {PVH }}$ neurons as a Sim $1^{\text {PVH }}$ neuronal subset. $\boldsymbol{C}, \boldsymbol{D}$, OXT ${ }^{\mathrm{PVH}}$ neurons are contained within the Nos $1^{\mathrm{PVH}}$ population (green), as shown by expression of OXT (red) in sections from Nos $7-i$ Cre, lox-GFP mice. E, A model of neurochemically defined cell types within the PVH. Dashed boxes indicate regions that are digitally enlarged and shown as insets. Arrowheads indicate representative overlapped cell-bodies. Scale bar, $200 \mu \mathrm{m}$. 3V, Third ventricle.

was homogenized in protein lysis buffer (10\% SDS, 1 м Tris, pH 6.8, 12.7 mM EDTA) with metal beads in a Bullet blender for $30 \mathrm{~min}$. Samples were clarified by centrifugation, and protein concentration was quantified by BCA assay (catalog \#23225, Thermo Scientific). Lysates were diluted to equal protein concentration in lysis buffer plus $1 \times$ NuPage SDS buffer (Invitrogen) with 2.5\% 2-mercaptoethanol. Samples were boiled for 5 min and loaded on an SDS gradient polyacrylamide gel (Invitrogen), and separated by electrophoresis. Proteins were transferred to Immobilon PVDF membranes (Millipore), and Ponceau staining of membranes was used to confirm equal protein loading between lanes. Membranes were blocked in 5\% milk for $1 \mathrm{~h}$ at room temperature and then incubated with primary antibodies (goat anti-UCP1, 1:2000, catalog \#SC-6528, Santa Cruz Biotechnology; rat anti- $\alpha$-tubulin, 1:1000, catalog \#MA1-80017, Thermo Scientific) and appropriate HRP-conjugated secondary antibodies (1:5000 dilution in 5\% milk, IgG peroxidase; GE Healthcare) in 5\% BSA. Super Signal enhanced chemiluminescence (Pierce) was used for visualization by autoradiography, and bands were quantified by densitometry.

Statistical analysis. Paired $t$ tests, unpaired $t$ tests, or repeatedmeasures two-way ANOVAs were calculated using GraphPad Prism. Significance was determined at $p<0.05$.

\section{Results}

nNos1 (Nos1) expression defines a PVH subpopulation

Nos1 in situ hybridization (Allen Brain Atlas) and Nos1-iCre, loxGFP reporter mice demonstrate the existence of NOS1containing neurons in the PVH. To determine whether NOS1 peptide marks a neuronal subset of the entire PVH, we stained brains from Sim1-Cre, lox-GFP reporter mice for GFP and NOS1 immunoreactivity (IR) and found that all Nos1 ${ }^{\mathrm{PVH}}$ neurons express Sim1, but not all Sim $1^{\mathrm{PVH}}$ neurons express NOS1 (Fig. $1 A, B)$. PVH cell counts in Sim1-Cre, lox-GFP brain slices immunostained for Nos1 peptide $(n=5)$ revealed that Nos $1^{\mathrm{PVH}}$ neurons account for $\sim 21 \%$ of the Sim $1^{\mathrm{PVH}}$ field. To identify some potential Nos1 ${ }^{\mathrm{PVH}}$ subtypes, we also investigated the overlap between Nos $1^{\mathrm{PVH}}$ and OXT ${ }^{\mathrm{PVH}}$ neurons. Using Nos1-iCre, lox-GFP sections, we found that almost all $\mathrm{OXT}^{\mathrm{PVH}}$ neurons $(\sim 90 \%, n=$ 3) contain GFP, whereas only $16 \%(n=3)$ of Nos1-iCre ${ }^{\mathrm{PVH}}$ neurons contain OXT peptide. This confirms that $\mathrm{OXT}^{\mathrm{PVH}}$ neurons are a subset of Nos1 ${ }^{\mathrm{PVH}}$ neurons (Fig. $1 C, D$ ). This establishes that Nos1 ${ }^{\mathrm{PVH}}$ neurons represent a discrete subset of $\mathrm{Sim}_{1}{ }^{\mathrm{PVH}}$ neurons and that most $\mathrm{OXT}^{\mathrm{PVH}}$ neurons lie within the Nos $1^{\mathrm{PVH}}$ field (Fig. 1E). Given the importance of Sim1 $1^{\mathrm{PVH}}$ neurons in energy balance regulation and the limited information regarding the roles of specific PVH subtypes in this regulation, we investigated the potential contributions of Nos1 ${ }^{\mathrm{PVH}}$ and $\mathrm{OXT}^{\mathrm{PVH}}$ neurons to the control of energy balance parameters.

\section{Nos $1^{\mathrm{PVH}}$ neurons send dense projections to hindbrain regions important for satiety}

As hindbrain regions [e.g., NTS/dorsal motor nucleus of the vagus (DMV), PBN, and specifically PVH $\rightarrow$ NTS neuronal projections] have been implicated in feeding regulation, we charac- 
A
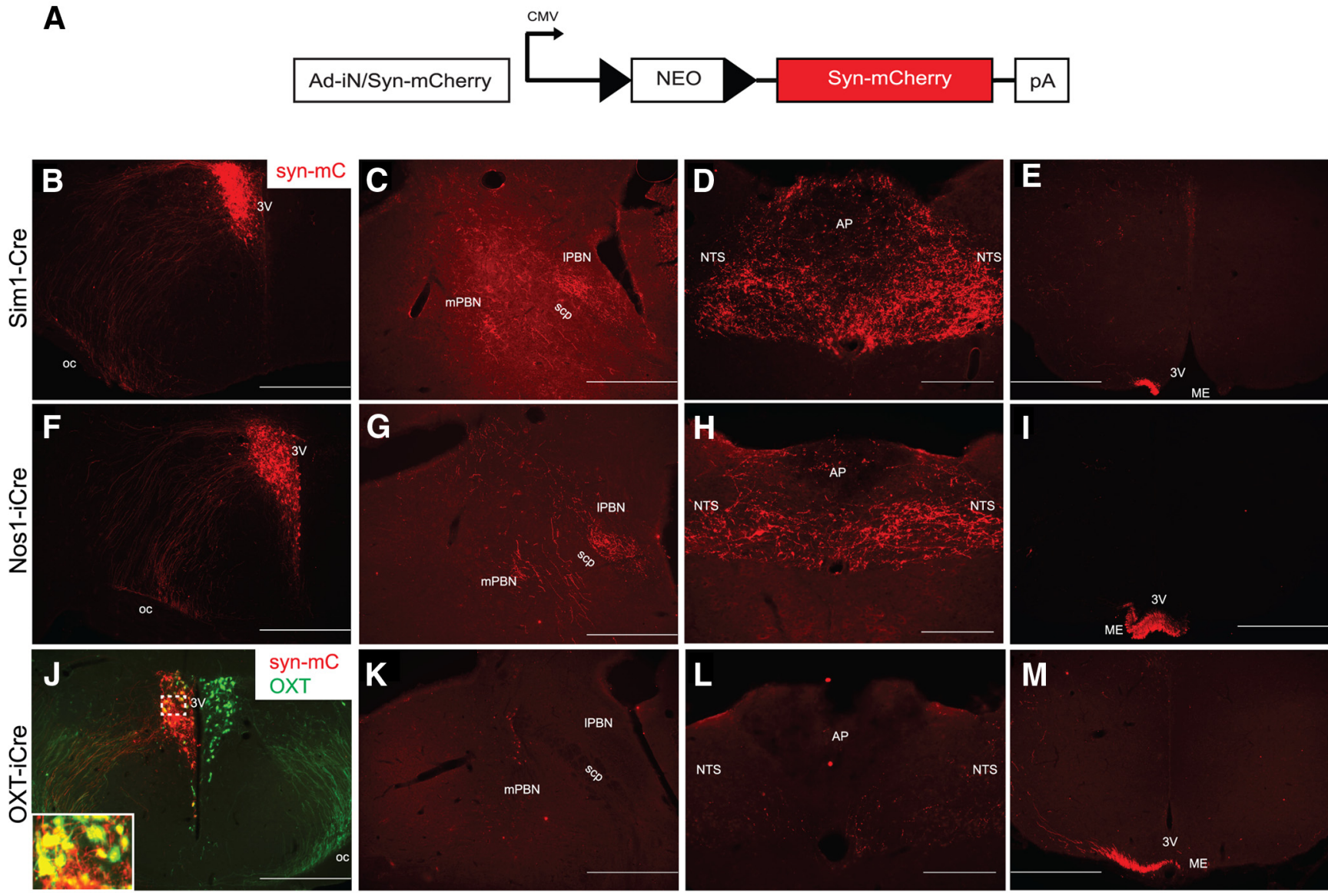

Figure 2. Nos $1^{\mathrm{PVH}}$ neurons project to hindbrain regions important for satiety. $A, A$ Cre-dependent synaptophysin-mCherry viral vector allows for anterograde tracing of projections in the CNS. $\boldsymbol{B}-\boldsymbol{E}$, Unilateral PVH-specific injections of Ad-iN/syn-mCherry in Sim1-Cre mice ( $B)$ identify projections to the parabrachial nucleus ( $\boldsymbol{C}$, nucleus of the solitary tract (D), and the median eminence (ME; E). $\boldsymbol{F}-\boldsymbol{I}$, Stereotaxic injection of Ad-iN/syn-mCherry in the PVH of Nos 1-iCre mice $(\boldsymbol{F})$ demonstrates similar projections to the PBN $(\boldsymbol{G})$, NTS $(\boldsymbol{H})$, or ME $(\boldsymbol{I})$. J-M, In contrast, injection of Ad-iN/syn$m$ Cherry in the PVH of OXT-iCre mice $(\boldsymbol{J})$ reveals few projections to either the PBN $(\boldsymbol{K})$ or NTS $(\boldsymbol{L})$, though projections to the ME are readily apparent $(\boldsymbol{M})$. $\boldsymbol{J}$, Sections were costained for OXT peptide (green) to show the fidelity of the Cre-dependent virus. Dashed boxes indicate regions that are digitally enlarged and shown as insets. Scale bars: D, H, L, $200 \mu \mathrm{m}$; all others, $500 \mu \mathrm{m}$. 3V, Third ventricle; scp, superior cerebellar peduncle; AP, area postrema; cc, central canal; ME, median eminence.

terized efferent projections from defined PVH subpopulations to the NTS/DMV and the PBN. We used Sim $1^{\mathrm{PVH}}$ neurons as a reference group to establish projection targets for comparison with Nos $1^{\mathrm{PVH}}$ and $\mathrm{OXT}^{\mathrm{PVH}}$ subsets. Sim1-Cre mice were unilaterally injected with a Cre-dependent Ad-iN/syn-mCherry tracer (Fig. 2A), which traffics predominantly to synaptic terminals and preferentially identifies projection terminals as opposed to axons of passage. We observed dense $\operatorname{Sim} 1^{\mathrm{PVH}}$ neuron-derived mCherry-IR (Fig. 2B) in hindbrain regions important for satiety, including the medial PBN (mPBN) and lateral PBN (lPBN; Fig. 2C) and the NTS (Fig. 2D). Similar mCherry-IR was observed in these hindbrain regions from Nos $1^{\mathrm{PVH}}$ neurons injected with Ad-iN/synmCherry (Fig. $2 F-H$ ). In contrast, we detected very little $\mathrm{OXT}^{\mathrm{PVH}}$ derived syn-mCherry in the PBN (Fig. $2 K$ ) or NTS (Fig. $2 L$ ). Unilateral PVH injections of Ad-iN/syn-mCherry in OXT-iCre mice demonstrated syn-mCherry expression (Fig. 2J, red) only in OXT$\mathrm{PVH}$ neurons (Fig. 2J, green), confirming the fidelity of the Credependent Ad-iN/syn-mCherry virus. As expected, Sim1 ${ }^{\mathrm{PVH}}$, Nos $1^{\mathrm{PVH}}$, and $\mathrm{OXT}^{\mathrm{PVH}}$ neurons also sent dense projections to the median eminence, reflecting the parvocellular PVH subpopulation projections that influence pituitary function and the magnocellular projections that release their contents directly from the posterior pituitary into the systemic circulation (Fig. 2E,I,M).

To better characterize the PVH neurons that project to the NTS/DMV and potentially affect feeding behaviors, we injected fluorescent latex microspheres (RRs, Lumafluor) unilaterally into the NTS of Sim1-Cre, lox-GFP, Nos1-iCre, lox-GFP, and wild-type mice (Fig. $3 A, E$, J, respectively). RRs are preferentially taken up by presynaptic terminals at the site of injection and undergo retrograde transportation back to the cell body, thus allowing neuron identification by autofluorescence. As might be expected, all RR-labeled PVH neurons from Sim1-Cre, loxGFP animals coexpress GFP, suggesting that all PVH $\rightarrow$ NTS projections originate from Sim $1^{\mathrm{PVH}}$ neurons (Fig. $3 B-D$ ). Retrograde labeling from the NTS/DMV in Nos1-iCre, lox-GFP mice also demonstrates extensive (but not complete) overlap between NTS-projecting RR-labeled neurons and Nos $1^{\mathrm{PVH}}$ neurons (Fig. $3 F-H)$. Since previous reports suggest the presence of $\mathrm{OXT}^{\mathrm{PVH}}$ projections to the NTS/DMV and essentially all $\mathrm{OXT}^{\mathrm{PVH}}$ neurons are within the Nos1-iCre ${ }^{\mathrm{PVH}}$ field, we costained Nos1-iCre, loxGFP mice with NTS RR injections for OXT peptide (Fig. $3 I^{I}-I^{I V}$ ). As expected, OXT-IR is seen within Nos $1^{\mathrm{PVH}}$ neurons (Fig. $3 I^{I V}$, green, open arrowheads); however, NTS-injected RRs predominantly labeled Nos $1^{\mathrm{PVH}}$ neurons that do not contain OXT (white arrowheads). In agreement with these findings, very few $\mathrm{OXT}^{\mathrm{PVH}}$ cell bodies were labeled with NTS-injected RRs (Fig. 3J-M) in separate control mice, even though OXT peptide (green) was detectable in the NTS/DMV at the site of the RR injection (Fig. $3 J)$. This suggests that much of the OXT-IR in the NTS identifies fibers of passage, as opposed to synaptic terminals. Nevertheless, 

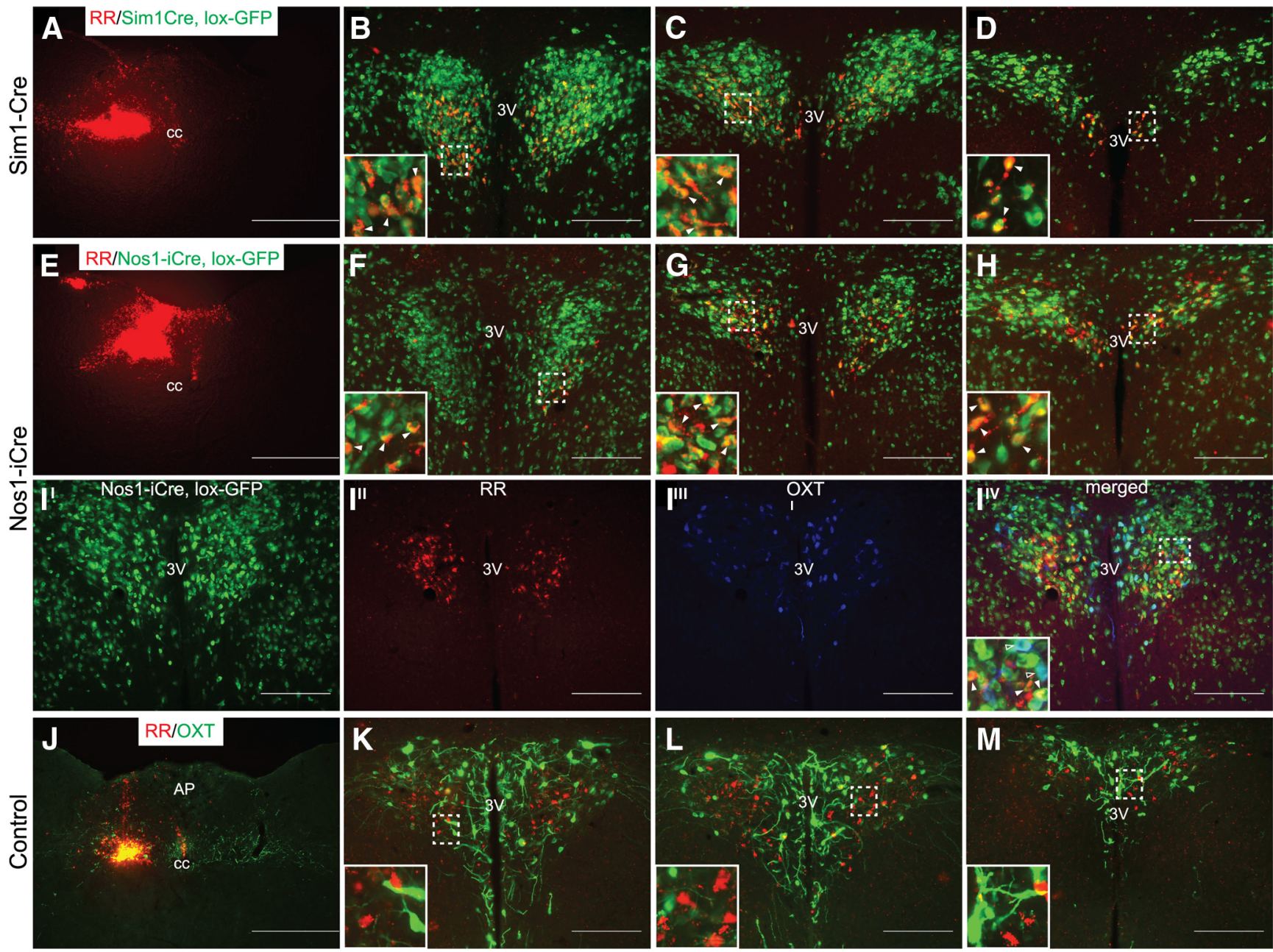

Figure 3. Retrograde labeling of PVH neurons from the NTS. $\boldsymbol{A}-\boldsymbol{H}$, RRs were injected in the hindbrains of in Sim 1-Cre, lox-GFP $(\boldsymbol{A})$ or Nos 1-iCre, lox-GFP (E) mice to identify NTS projecting Sim 1 $1^{\text {PVH }}$ $(\boldsymbol{B}-\boldsymbol{D})$ and $\operatorname{Nos}^{\mathrm{PVH}}(\boldsymbol{F}-\boldsymbol{H})$ neurons. $\boldsymbol{I}$, Additional sections from Nos 1 -iCre, lox-GFP mice $\left(\boldsymbol{I}^{\prime}\right)$ with hindbrain RR injections (same injection shown in $\left.\boldsymbol{E}\right)$ were stained for OXT peptide $\left(\boldsymbol{I}^{\prime \prime \prime}\right)$ and show that RR-labeled Nos1 neurons $\left(I^{\prime \prime}\right)$ do not contain OXT peptide ( $I^{\prime V}$, white arrowheads). OXT neurons only colocalize with Nos1, but not RR ( $I^{\prime V}$, open arrowheads). $J-M$, Furthermore, RR injected in the NTS of control mice $(J)$ do not colocalize with OXT peptide (green) in the PVH $(J-M)$. At the site of injection, beads appear in both green and red channels due to bead intensity (note yellow injection site). Immunohistochemistry identifies OXT peptide (green) expression near the injection site $(\boldsymbol{J})$. Dashed boxes indicate regions that are digitally enlarged and shown as insets. Arrowheads indicate representative overlapped cell-bodies. Scale bars: $A, E, J, 500 \mu \mathrm{m}$; all others, $200 \mu \mathrm{m}$. AP, Area postrema; cc, central canal; 3V, third ventricle.

it is the non-OXT Nos1 $1^{\mathrm{PVH}}$ neurons that comprise the bulk of the NTS-projecting Nos1 ${ }^{\mathrm{PVH}}$ neurons.

Nos1 ${ }^{\mathrm{PVH}}$ and $\mathrm{OXT}^{\mathrm{PVH}}$ neurons project to the spinal cord

Since sympathetic outflow promotes energy expenditure and the PVH is implicated in energy expenditure regulation, we also investigated whether $\mathrm{Nos}^{\mathrm{PVH}}$ and $\mathrm{OXT}^{\mathrm{PVH}}$ neurons project to hindbrain and spinal cord regions important for SNS control (Cowley et al., 1999; Xi et al., 2012). The raphe pallidus (RPa) is an important hindbrain region controlling BAT function and energy expenditure (Bamshad et al., 1999; Morrison, 1999; Cano et al., 2003). We found few syn-mCherry terminals originating from Sim $1^{\mathrm{PVH}}$ (Fig. 4A), Nos1 ${ }^{\mathrm{PVH}}$ (Fig. 4B), or OXT ${ }^{\mathrm{PVH}}$ (Fig. 4C) neurons in the RPa. To determine whether Sim $1^{\mathrm{PVH}}$, Nos $1^{\mathrm{PVH}}$, and $\mathrm{OXT}^{\mathrm{PVH}}$ neurons project to the preganglionic, sympathetic output neurons of the thoracic spinal cord, we also examined longitudinal spinal cord sections from Sim1-Cre, Nos1-iCre, or OXT-iCre mice following unilateral PVH Ad-iN/syn-mCherry injections. We identified robust syn-mCherry tracer in thoracic spinal cord regions originating from $\operatorname{Sim}_{1}{ }^{\mathrm{PVH}}$ (Fig. $4 D$ ), Nos $1^{\mathrm{PVH}}$ (Fig. $4 E$ ), and $\mathrm{OXT}^{\mathrm{PVH}}$ neurons (Fig. $4 F$ ). Syn-mCherry-IR is localized in close proximity to neurons expressing ChAT in the $\mathrm{ChAT}^{\mathrm{IML}}$, suggesting potential Sim $1^{\mathrm{PVH}}$, Nos $1^{\mathrm{PVH}}$, and $\mathrm{OXT}^{\mathrm{PVH}}$ neuronal connections with and regulation of IML preganglionic sympathetic neurons (Fig. $4 D^{\prime}, E^{\prime}, F^{\prime}$ ).

\section{Temporal control of PVH neuronal subpopulations}

Having established the anterograde projection targets for $\mathrm{Sim}_{1}{ }^{\mathrm{PVH}}$, Nos $1^{\mathrm{PVH}}$, and $\mathrm{OXT}^{\mathrm{PVH}}$ neurons, we tested the physiologic effects of acute activation of these PVH neurons on feeding and energy expenditure. To selectively activate these PVH subsets, we used Designer Receptors Exclusively Activated by Designer Drugs (DREADDs) technology (Alexander et al., 2009). The hM3Dq DREADD is a modified human muscarinic receptor designed to couple with stimulatory Gq-proteins. Binding of an otherwise inert, synthetic ligand, $\mathrm{CNO}$, activates neurons expressing hM3Dq. This system has been engineered to be Cre recombinase-dependent to achieve cell-specific control (Fig. $5 \mathrm{~A}$ ). Thus, site-specific injection of a Cre-dependent adeno-associated virus (AAV)-hM3Dq allows for remote and temporal activation only of neurons that express Cre recombinase. As for our tracing studies, we used Sim1-Cre mice to target the majority of PVH 

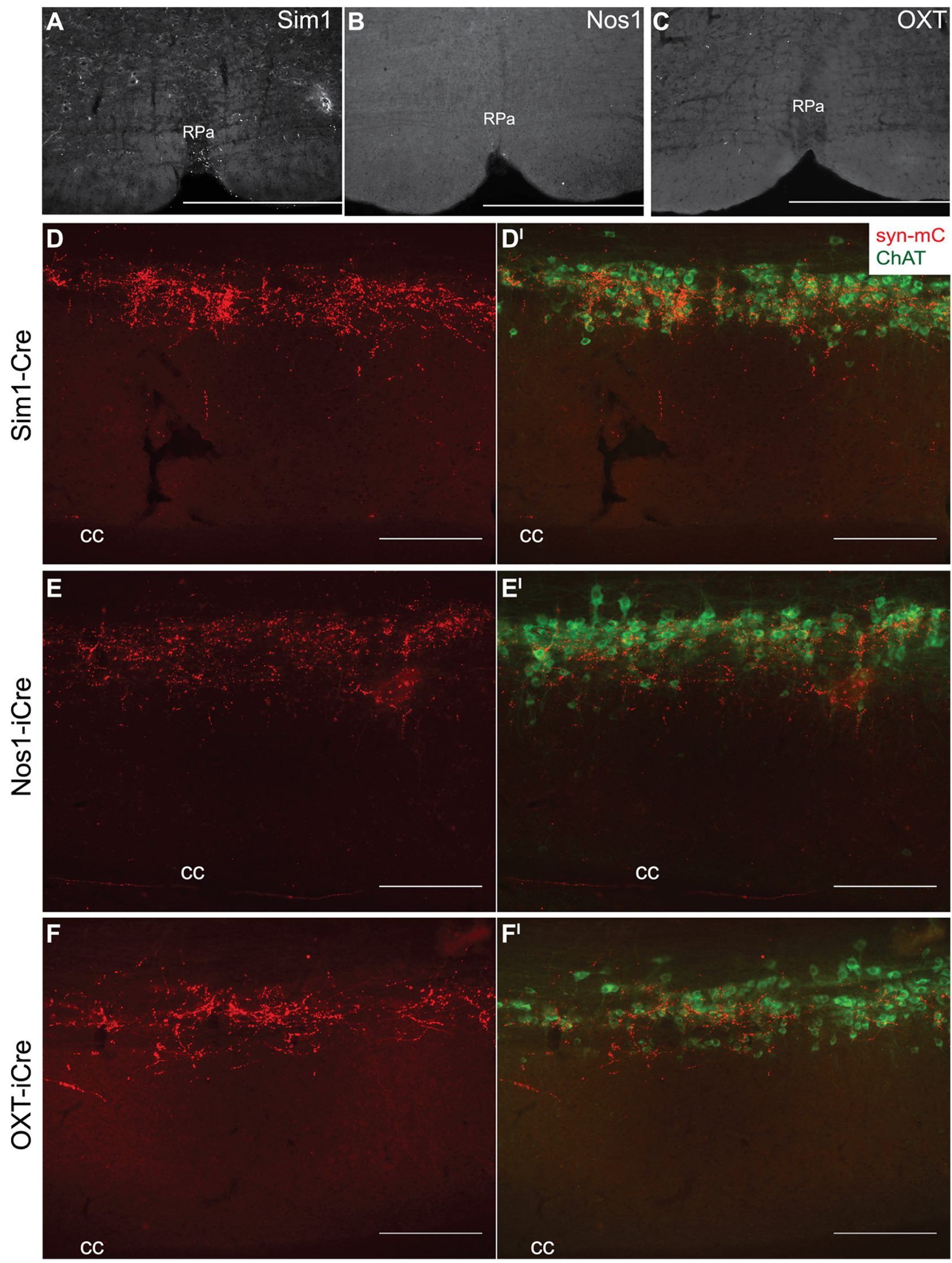

Figure 4. Nos $1^{\mathrm{PVH}}$ and $\mathrm{OXT} \mathrm{T}^{\mathrm{PVH}}$ neurons project to preganglionic neurons in the spinal cord. $\boldsymbol{A}-\boldsymbol{C}$, Sim 1-Cre $(\boldsymbol{A})$, Nos 1-iCre $(\boldsymbol{B})$, or OXT-i(re $(\boldsymbol{C})$ mice with unilateral Ad-iN/syn-mCherry injections (red) show few projections to the RPa. $\boldsymbol{D}-\boldsymbol{F}$, In contrast, $\operatorname{Sim}^{\mathrm{PVH}}(\boldsymbol{D})$, Nos $\mathrm{P}^{\mathrm{PVH}}(\boldsymbol{E})$, and $\mathrm{OXT}^{\mathrm{PVH}}(\boldsymbol{F})$ all innervate thoracic spinal cord regions in close proximity to cholinergic neurons of the intermediolateral column expressing ChAT (green; $\boldsymbol{D}^{\prime}, \boldsymbol{E}^{\prime}, \boldsymbol{F}^{\prime}$ ). Scale bars: $\boldsymbol{A}-\boldsymbol{C}, 500 \mu \mathrm{m} ; \boldsymbol{D}-\boldsymbol{F}, 200 \mu \mathrm{m}$. cc, Central canal. 
A
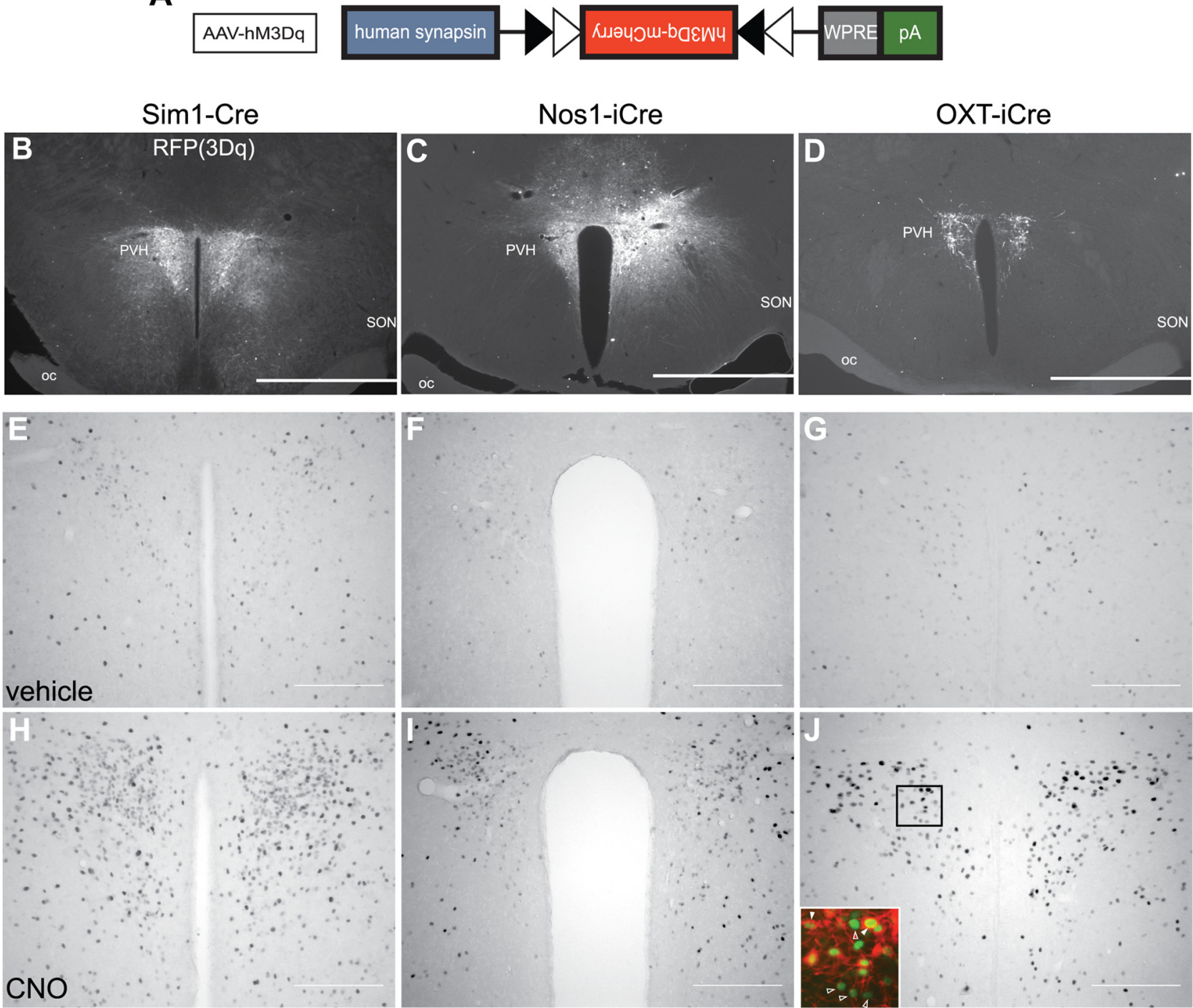

Figure 5. DREADDs allow for remote and temporal control of PVH neuronal activity. $\boldsymbol{A}$, Diagram of the Cre-dependent hM3Dq DREADDs expression vector. $\boldsymbol{B}-\boldsymbol{D}$, Expression of AAV-hM3Dq-

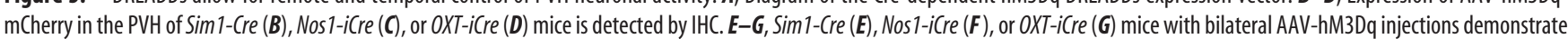
little nuclear Fos immunoreactivity after treatment with vehicle. $\boldsymbol{H}-\boldsymbol{J}$, In contrast, PVH neurons expressing hM3Dq are activated following injection of $\mathrm{CNO}^{\mathrm{C}}$. OXT ${ }^{\mathrm{PVH}}$ neuronal activation leads to nuclear Fos expression (J, inset, green) not only in hM3Dq-expressing OXT ${ }^{\mathrm{PVH}}$ neurons ( $\boldsymbol{J}$, inset, red, closed arrowheads), but also in neighboring non-OXT ${ }^{\mathrm{PVH}}$ neurons (open arrowheads). Scale bars: $B-D, 1 \mathrm{~mm} ; E-J, 200 \mu \mathrm{m} .0$ OC, Optic chiasm.

neurons and to establish an upper threshold of PVH "output capacity" upon DREADD activation followed by Nos $1^{\mathrm{PVH}}$ and $\mathrm{OXT}^{\mathrm{PVH}}$ subset activation. As a control for DREADD injection, bilateral PVH injections of AAV-hM3Dq into WT mice were also performed.

Although AAV-hM3Dq was primarily limited to the PVH of Sim1-Cre-injected mice, there was a small amount of AAVhM3Dq expression in Sim1-Cre ${ }^{+}$areas in the anterior hypothalamus (Fig. 5B). Similarly, while injections in Nos1-iCre mice were targeted for the PVH, some Nos1-iCre ${ }^{+}$neurons in the thalamus also expressed hM3Dq (Fig. 5C). Importantly, any injected Nos1iCre animals that expressed hM3Dq in peri-PVH areas implicated in feeding (i.e., dorsomedial hypothalamus) were excluded from the analysis. PVH injections of AAV-hM3Dq were restricted to $\mathrm{OXT}^{\mathrm{PVH}}$ neurons, as Cre expression in $O X T$-iCre mice is limited to the PVH and supraoptic nucleus (SON; Fig. 5D). Using nuclear Fos staining as an indicator of neuronal activation, vehicle injection caused little PVH activation in Sim1-Cre (Fig.
5E), Nos1-iCre (Fig. 5F), or OXT-iCre (Fig. 5G) mice with bilateral PVH AAV-hM3Dq injections. In contrast, hM3Dq-injected mice treated with $\mathrm{CNO}$ before perfusion demonstrated a marked increase in nuclear Fos staining in transduced PVH neurons (Fig. $5 H-J)$. Specifically, CNO stimulated PVH nuclear Fos expression in Sim1-Cre+AAV-hM3Dq mice [176.5 \pm 6.5 vs $51.0 \pm 6.0$ (vehicle); $n=2$ each; unpaired $t$ test, $\left.t_{(2)}=14.2, p=0.005\right)$, Nos1$i \mathrm{Cre}+\mathrm{AAV}-\mathrm{hM} 3 \mathrm{Dq}$ mice $(200.7 \pm 39.0$ vs $36.0 \pm 5.0$ (vehicle); vehicle, $n=2$; CNO, $n=3$; unpaired $t$ test, $\left.t_{(3)}=3.3, p=0.047\right]$ and $O X T$-iCre $+\mathrm{AAV}-\mathrm{hM} 3 \mathrm{Dq}$ mice $[130 \pm 14$ vs $63.0 \pm 5.1$ (vehicle); $n=4$ each; unpaired $t$ test, $\left.t_{(6)}=4.4, p=0.005\right]$. This demonstrates that cell-specific DREADD expression allows for temporal control of PVH neuron activity. Nuclear Fos was also apparent in non-Cre-expressing cells, suggesting that PVH subtypes can activate neighboring PVH cells via local connections (Fig. 5J, inset; Boudaba et al., 1996; Ziegler and Herman, 2000). We detected no hM3Dq expression or CNO-dependent activation in the PVH of wild-type control mice (data not shown). 


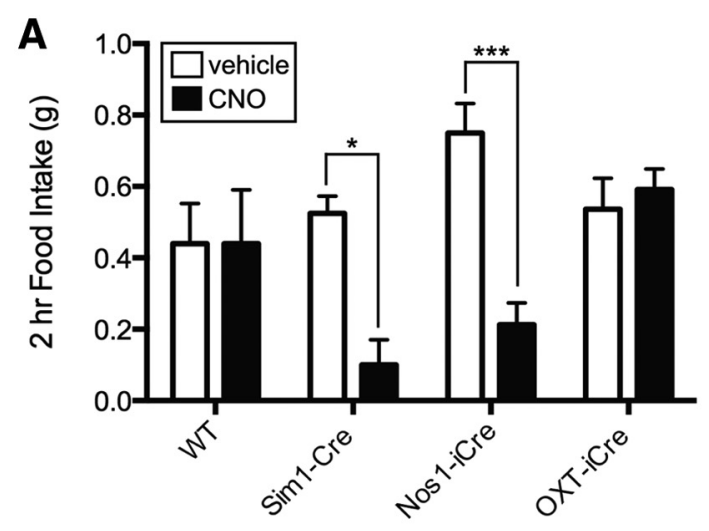

B
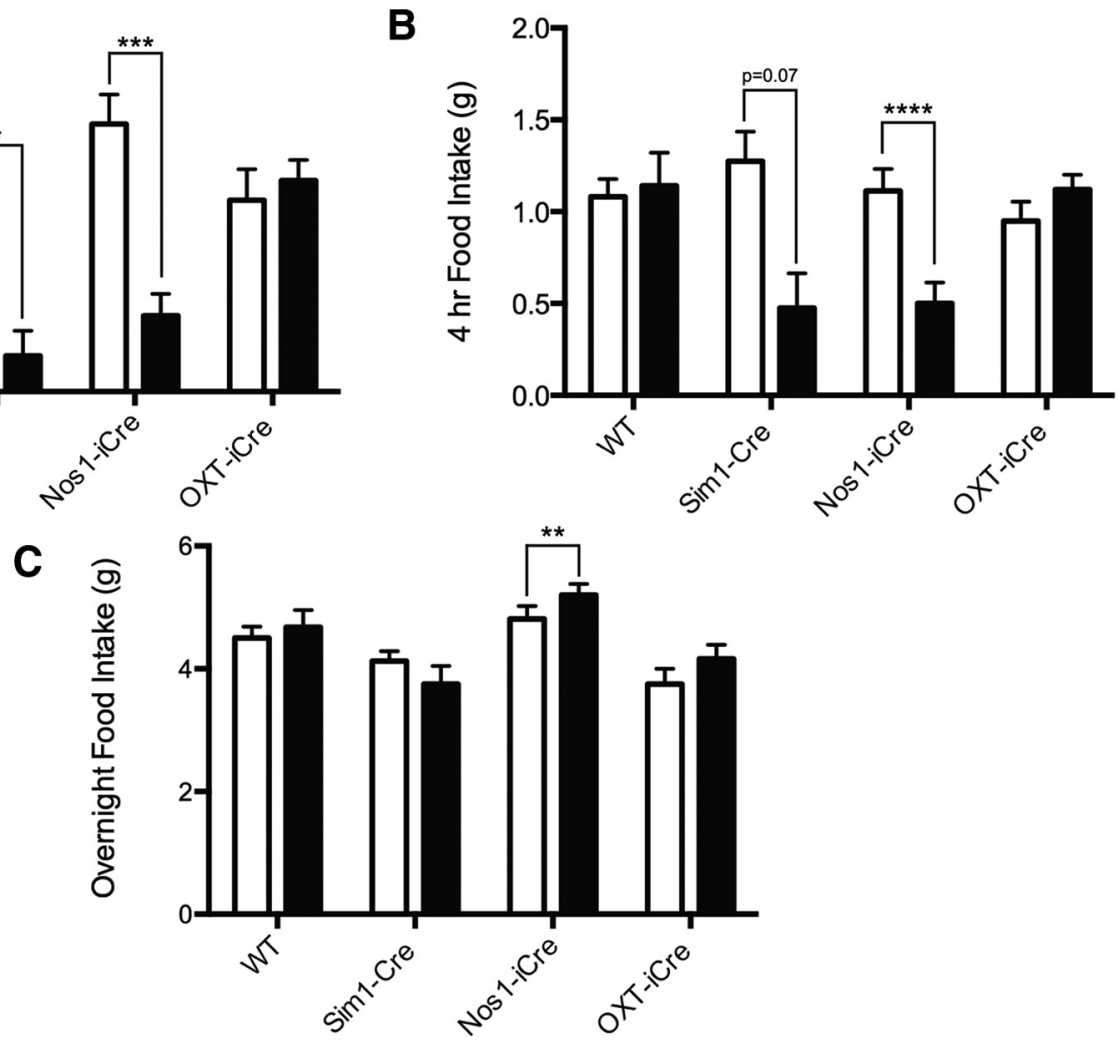

Figure 6. Acute activation of Nos $1^{\text {PVH }}$ neurons suppresses feeding. WT + AAV-hM3Dq, Sim1-Cre + AAV-hM3Dq, Nos 1-iCre, or OXT-iCre + AAV-hM3Dq mice were injected with vehicle (white bars) or CNO (black bars). A, Activation of Sim $1^{\mathrm{PVH}}$ or Nos $\mathrm{P}^{\mathrm{PVH}}$ neurons decreases $2 \mathrm{~h}$ food intake whereas activation of $0 \mathrm{XT}^{\mathrm{PVH}}$ neurons had no effect on food intake. $B$, Activation of Nos $1^{\mathrm{PVH}}$ neurons also significantly decrease $4 \mathrm{~h}$ food intake, and Sim $1^{\mathrm{PVH}}$ neuronal activation shows a similar trend, though this is not significant. C, Cumulative overnight food intake ( $16 \mathrm{~h}$ ) is not altered by activation of PVH neuronal subsets. Average values \pm SEM are shown. ${ }^{*} p<0.05,{ }^{* * *} p<0.01,{ }^{* * * *} p<0.0001$ compared with vehicle values (WT, $n=5 ; \operatorname{Sim} 1-$ Cre,$n=4 ;$ Nos $1-i$ Cre,$n=8 ;$ OXT-iCre, $n=$ 10). Significance was determined using two-tailed paired $t$ test.

\section{Direct activation of PVH neurons alters food intake}

Based on our anterograde tracing of PVH subsets, we hypothesized that activation of Sim $1^{\mathrm{PVH}}$ and Nos $1^{\mathrm{PVH}}$ neurons would alter feeding (via projections to hindbrain regions). To test this hypothesis, we injected AAV-hM3Dq bilaterally into the PVH of Sim1-Cre, Nos1-iCre, and OXT-iCre mice, and treated these animals with $\mathrm{CNO}(0.3 \mathrm{mg} / \mathrm{kg})$ at the onset of dark cycle feeding. Body weights ( \pm SEM) of the animals used in these studies are as follows: Sim1-Cre, $22.6 \pm 1.6 \mathrm{~g}(n=4) ;$ Nos1-iCre, $25.6 \pm 0.7 \mathrm{~g}$ $(n=8)$; OXT-iCre, $22.8 \pm 0.8 \mathrm{~g}(n=10)$; WT, $24.1 \pm 0.8 \mathrm{~g}(n=$ 4). Wild-type controls with bilateral PVH AAV-hM3Dq injections showed no change in feeding behavior in response to $\mathrm{CNO}$ compared with vehicle injections, demonstrating that neither viral transduction nor $\mathrm{CNO}$ alone altered food intake (Fig. 6A, first panel). Activation of Sim $1{ }^{\mathrm{PVH}}$ neurons robustly suppressed feeding compared with vehicle control (Fig. $6 \mathrm{~A}$, second panel; paired $t$ test, $\left.t_{(3)}=5.0, p=0.015\right)$. As hypothesized, Nos1-iCre mice with bilateral AAV-hM3Dq injections also ate significantly less following CNO activation of $\operatorname{Nos}_{1}{ }^{\mathrm{PVH}}$ neurons compared with vehicle (Fig. $6 A$, third panel; paired $t$ test, $t_{(7)}=7.9, p<0.0001$ ). Interestingly, the $2 \mathrm{~h}$ suppression of food intake following activation of $\operatorname{Sim} 1^{\mathrm{PVH}}$ and Nos $1^{\mathrm{PVH}}$ neurons is comparable $\left(t_{(10)}=1.0, p=\right.$ 0.35 , unpaired $t$ test), suggesting that the anorexia associated with $\operatorname{Sim} 1{ }^{\mathrm{PVH}}$ activation is mediated largely via Nos $1^{\mathrm{PVH}}$ neurons. The anorectic effect of Nos $1^{\mathrm{PVH}}$ activation persists through $4 \mathrm{~h}$ of refeeding (paired $t$ test, $t_{(7)}=11.2, p<0.0001$; there is a similar trend for Sim $1^{\mathrm{PVH}}$ neuron activation; Fig. $\left.6 B\right)$, although total overnight food intake $(16 \mathrm{~h})$ approximates that of controls (Fig. $6 C)$. In contrast to $\operatorname{Sim} 1^{\mathrm{PVH}}$ and $\mathrm{Nos} 1^{\mathrm{PVH}}$ neurons, activation of
$\mathrm{OXT}^{\mathrm{PVH}}$ neurons had little effect on 2 or $4 \mathrm{~h}$ food intake (Fig. $6 A, B$, fourth panel). Thus, Nos $1^{\mathrm{PVH}}$ neuron activation suppresses feeding to a similar extent as $\operatorname{Sim} 1^{\mathrm{PVH}}$ neurons, suggesting a major role for Nos1 ${ }^{\mathrm{PVH}}$ neurons in the control of food intake. Furthermore, since activation of the OXT-containing subset of Nos $1^{\mathrm{PVH}}$ neurons fails to blunt feeding, the activation of non-OXT Nos $1^{\mathrm{PVH}}$ neurons must be required for this effect.

\section{Activation of PVH neurons increases Fos expression} in sympathetic output neurons and promotes energy expenditure

The role of the PVH in modulating energy expenditure has received less attention than its contribution to feeding regulation. Given the robust spinal cord projections from Sim $1^{\mathrm{PVH}}$, Nos $1^{\mathrm{PVH}}$, and $\mathrm{OXT}^{\mathrm{PVH}}$ neurons, we determined the effect of DREADD-mediated activation of these PVH neural subsets on nuclear Fos expression in preganglionic, sympathetic output neurons and overall oxygen consumption. First, we treated Sim1-Cre+AAV-hM3Dq, Nos1-iCre+AAV-hM3Dq, or OXTiCre+AAV-hM3Dq mice with vehicle (Fig. 7A,C,E) or $\mathrm{CNO}$ (Fig. $7 B, D, F$ ) and analyzed thoracic spinal cord sections for nuclear Fos accumulation in ChAT ${ }^{\mathrm{IML}}$ neurons. Acute activation of $\operatorname{Sim} 1^{\mathrm{PVH}}, \mathrm{Nos}^{\mathrm{PVH}}$, and $\mathrm{OXT}^{\mathrm{PVH}}$ neurons all appeared to increase nuclear Fos expression in $\mathrm{ChAT}^{\mathrm{IML}}$ neurons relative to vehicle control. To estimate this effect, we determined the percentage of ChAT $^{\mathrm{IML}}$ neurons containing nuclear Fos immunoreactivity in thoracic spinal cord sections from Sim1$\mathrm{Cre}+\mathrm{AAV}-\mathrm{hM} 3 \mathrm{Dq}$ mice in response to $\mathrm{CNO}$ versus vehicle. Activation of Sim $1^{\mathrm{PVH}}$ neurons showed a trend toward increased 

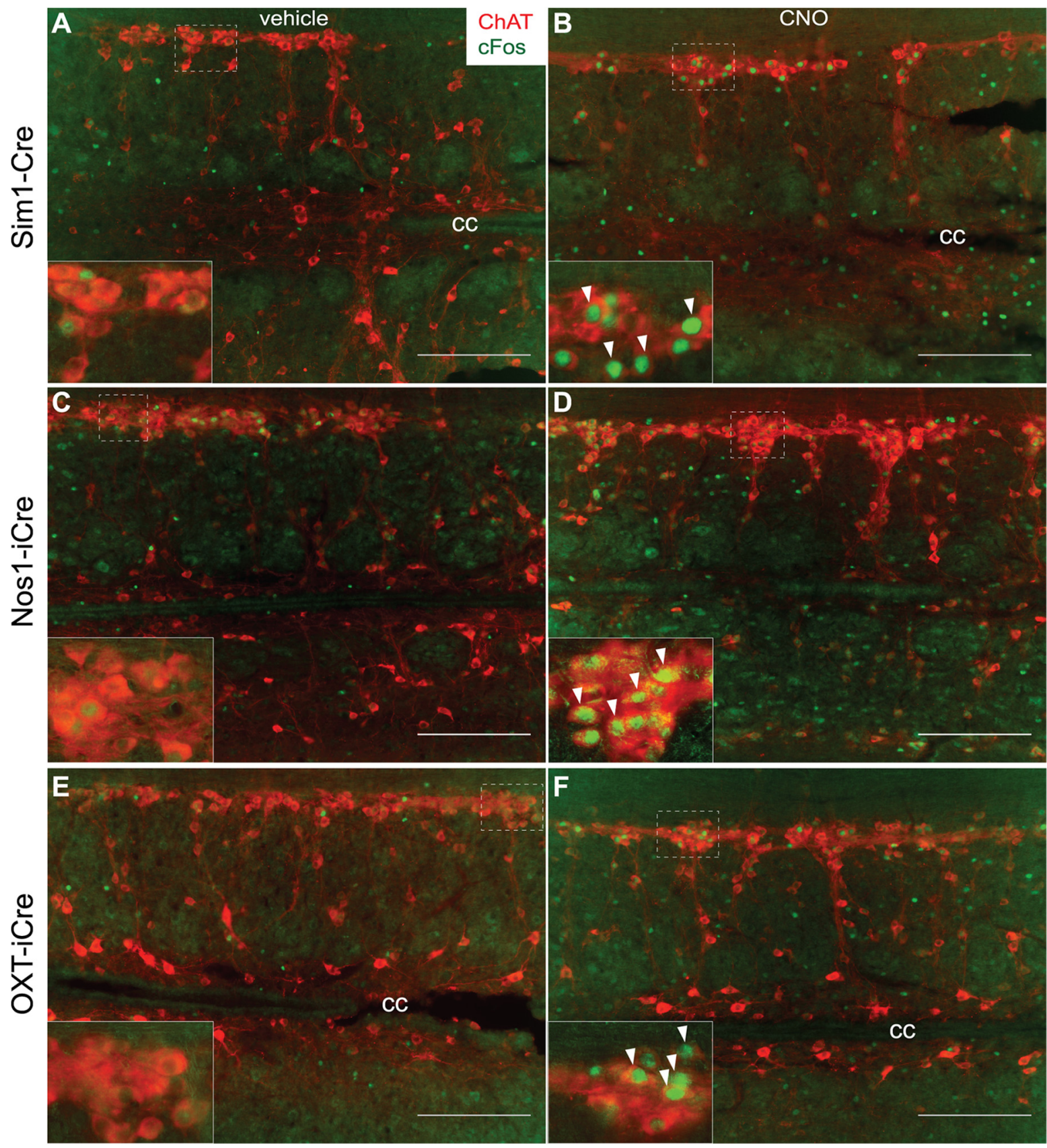

Figure 7. Nos $1^{\mathrm{PVH}}$ and $\mathrm{OXT} \mathrm{PVH}^{\mathrm{PVH}}$ neurons can activate ChAT ${ }^{\mathrm{IML}}$ neurons. $\boldsymbol{A}-\boldsymbol{F}$, While basal neuronal activity of ChAT ${ }^{\mathrm{IML}}$ neurons is minimal in Sim 1-Cre + AAV-hM3Dq $(\boldsymbol{A})$, Nos $1-i(\mathrm{Cre}+\mathrm{AAV}-\mathrm{hM} 3 \mathrm{Dq}$ $(\boldsymbol{C})$, or OXT-iCre + AAV-hM3Dq (E) mice injected with vehicle, CNO-mediated activation of Sim1 ${ }^{\mathrm{PVH}}(\boldsymbol{B})$, Nos $1^{\mathrm{PVH}}(\boldsymbol{D})$, or OXT ${ }^{\mathrm{PVH}}(\boldsymbol{F})$ neurons increases nuclear Fos (green) in IML ChAT neurons (red). Scale bars, $200 \mu \mathrm{m}$. Dashed white boxes identify regions where $40 \times$ inset images were taken. Arrowheads indicate representative overlapped cell bodies and Fos-IR nuclei upon treatment with CNO. Scale bars, $200 \mu \mathrm{m}$. cc, Central canal.

nuclear Fos expression in ChAT ${ }^{\mathrm{IML}}$ neurons with $42.6 \pm 7.2 \%$ (CNO-treated) versus $16.1 \pm 5.4 \%$ (vehicle-treated) $\mathrm{ChAT}^{\mathrm{IML}}$ neurons counted ( $n=2$ each; unpaired $t$ test, $t_{(2)}=2.9, p=$ 0.099 ). These data thereby suggest a potential neuroanatomical pathway for the regulation of sympathetic output and energy expenditure.

To determine the ability of each PVH subset to modulate energy expenditure, we used metabolic cages to measure $\mathrm{VO}_{2}$ and locomotor activity in animals expressing hM3Dq in $\mathrm{Sim}^{\mathrm{PVH}}$, Nos $1^{\mathrm{PVH}}$, and OXT ${ }^{\mathrm{PVH}}$ neurons. Activation of Sim $1^{\mathrm{PVH}}$ neurons and Nos $1^{\mathrm{PVH}}$ neurons increased the average oxygen consumption in the absence of food [Fig. $8 A, B$, second and third panels;
Sim 1: paired $t$ test; average $4 \mathrm{~h} \mathrm{VO}_{2}, t_{(3)}=8.8, p=0.003$; average $4 \mathrm{~h} \mathrm{VO}_{2}$ lean body mass (LBM), $t_{(3)}=11.0, p=0.002$; Nos 1 : average $4 \mathrm{~h} \mathrm{VO}_{2}, t_{(3)}=3.2, p=0.05$; average $4 \mathrm{~h} \mathrm{VO}_{2} \mathrm{LBM}, t_{(3)}=$ $3.6 p=0.038]$. Acute activation of $\mathrm{OXT}^{\mathrm{PVH}}$ neurons also significantly increased oxygen consumption (Fig. $8 A, B$, fourth panel; average $4 \mathrm{~h} \mathrm{VO}_{2}, t_{(9)}=2.4, p=0.042$; average $4 \mathrm{~h} \mathrm{VO} \mathrm{VO}_{2} \mathrm{LBM}$, $t_{(9)}=2.3, p=0.05$ ), albeit not to the extent seen with activation of Nos $1^{\mathrm{PVH}}$ neurons (unpaired $t$ test of average change in $4 \mathrm{~h} \mathrm{VO}_{2}$, $\left.t_{(13)}=2.5, p=0.029\right)$. Baseline oxygen consumption was elevated in the initial cohort of OXT-iCre +AAV-hM3Dq mice compared with other groups (one-way ANOVA of the average change in $\left.4 \mathrm{~h} \mathrm{VO}_{2}, F_{(3,19)}=7.3, p=0.002\right)$. To exclude the possibility 
A

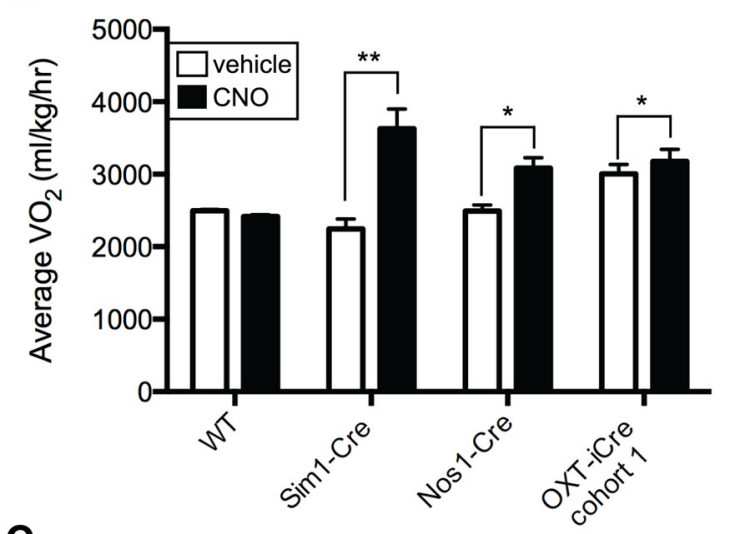

C

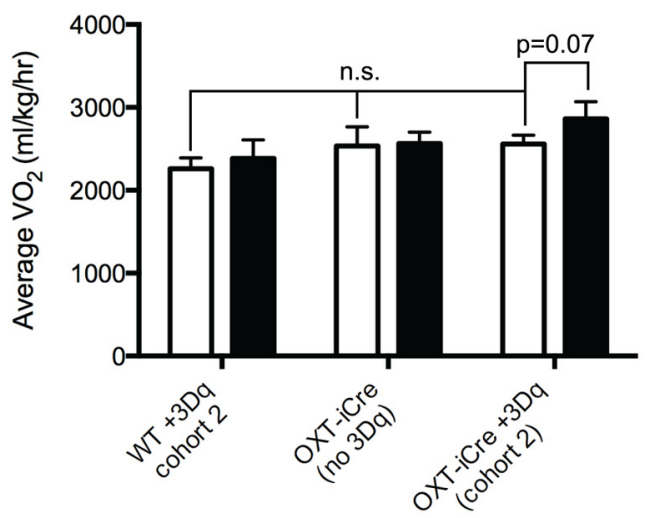

E

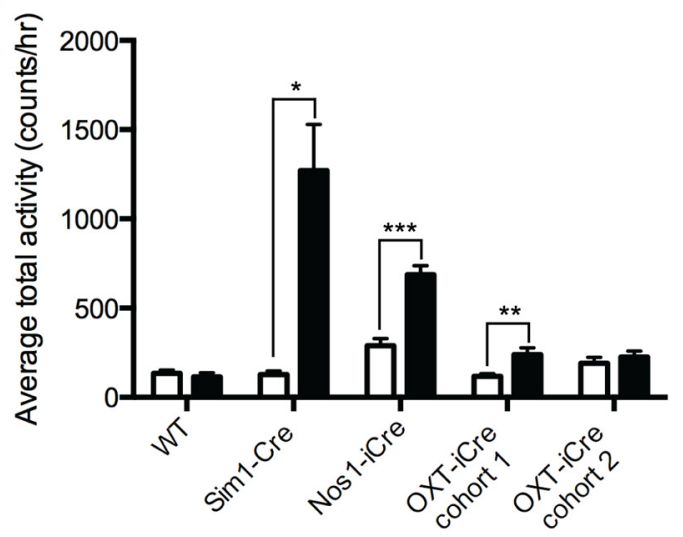

B

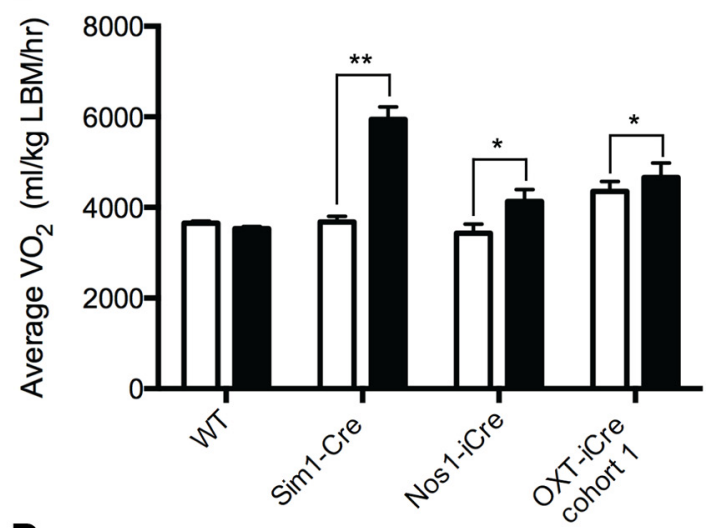

D

F
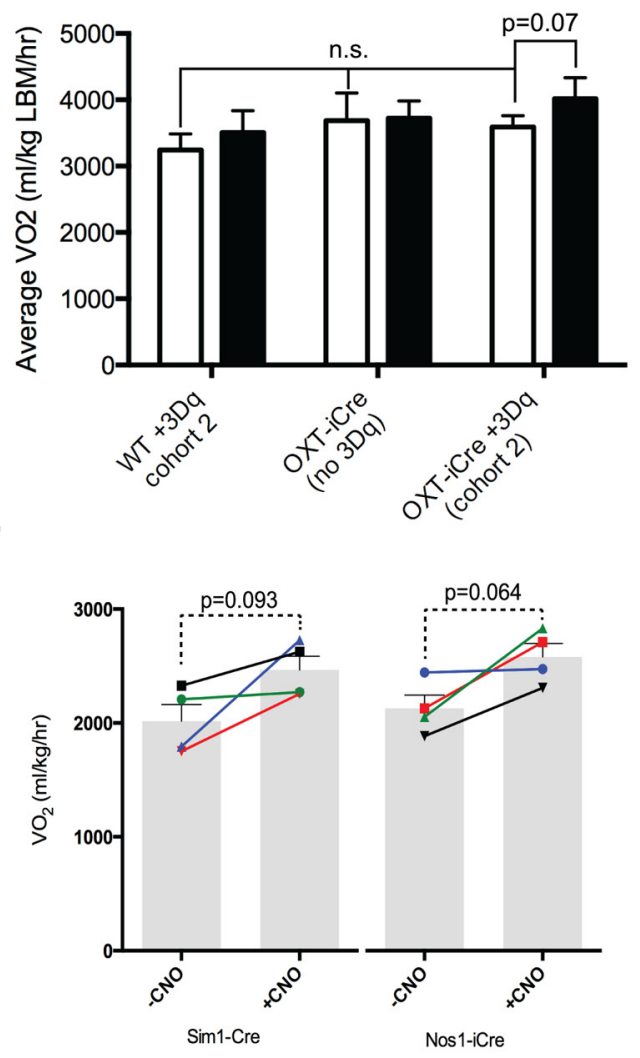

Figure 8. Acute activation of Nos1 ${ }^{\mathrm{PVH}}$ neurons increases energy expenditure. WT+AAV-hM3Dq, Sim1-Cre +AAV-hM3Dq, and Nos1-iCre or OXT-iCre +AAV-hM3Dq mice were injected with vehicle (white bars) or CNO (black bars). $\boldsymbol{A}, \boldsymbol{B}, \boldsymbol{E}$, Activation of Sim $1^{\mathrm{PVH}},{ }_{\text {Nos }}{ }^{\mathrm{PVH}}$ or OXT ${ }^{\mathrm{PVH}}$ neurons increases average oxygen consumption $(\boldsymbol{A}, \boldsymbol{B})$ and total activity $(\boldsymbol{E})$ over $4 \mathrm{~h}$ following injection. $\boldsymbol{C}$, $D, A$ second cohort of CNO-naive mice also shows a trend toward increased $4 \mathrm{~h}$ average $\mathrm{VO}_{2}$ in response to activation of $\mathrm{OXT}^{\mathrm{PVH}}$ neurons, while baseline VO${ }_{2}$ is unchanged compared with $\mathrm{WT}+3 \mathrm{Dq}$ or OXT-iCre mice without 3Dq injections (WT, $n=5 ;$ Sim1-Cre, $n=4 ;$ Nos1-iCre, $n=4 ;$ OXT-iCre cohort 1, $n=10 ;$ WT cohort 2, $n=4 ; 0 X T-i C r e+3 D q$ cohort 2, $n=4 ; 0 X T-i C r e, n=4)$. F, To determine potential activity-independent changes in $\mathrm{VO}_{2}, \mathrm{VO}_{2}$ was determined in Sim 1-Cre + 3Dq and Nos 1-iCre + 3Dq mice before and after CNO treatment, at time points when locomotor activity was approximately matched at activity levels below a threshold value of 300 counts/h (bars indicate average values \pm SEM, line segments indicate individual mice; Sim1, $n=4$; Nos1, $n=4$ ). Average values \pm SEM are shown. ${ }^{*} p<0.05,{ }^{* *} p<0.01,{ }^{* *} p<0.001$ compared with vehicle values. Significance was determined using two-tailed paired $t$ test within groups or unpaired $t$ test between groups.

that this elevated baseline $\mathrm{O}_{2}$ consumption was a property of the OXT-iCre transgenic line, as opposed to a cohort effect, oxygen consumption experiments were repeated in a second cohort of mice naive to $\mathrm{CNO}$ (Fig. 8C,D). Indeed, OXT-iCre+AAV-hM3Dq mice treated with vehicle had the same baseline oxygen consumption as WT and OXT-iCre mice without AAV-hM3Dq (one-way ANOVA of average change in $4 \mathrm{~h} \mathrm{VO}_{2}, F_{(2,9)}=1.0, p=0.4$ ), indicating that OXT-iCre mice are not metabolically compromised.

Interestingly, activation of any of the PVH subpopulations increased average total activity, although not equally (Fig. 8E; paired $t$ test; $\operatorname{Sim} 1+3 \mathrm{Dq}, t_{(3)}=4.7, p=0.019$; Nos $1+3 \mathrm{Dq}, t_{(3)}=$ $\left.26.8, p=0.0001 ; \mathrm{OXT}+3 \mathrm{Dq}, t_{(9)}=4.3, p=0.002\right)$. As expected, $\mathrm{WT}+\mathrm{AAV}$-hM3Dq mice showed no change in oxygen consumption or activity in response to $\mathrm{CNO}$ (Fig. $8 A-E$ ). Body weights ( \pm SEM) of the animals used in these studies are as follows: Sim1Cre, $30.5 \pm 2.1 \mathrm{~g}(n=4) ;$ Nos1-iCre, $29.4 \pm 0.9 \mathrm{~g}(n=4)$; OXT-iCre $+3 D q$ cohort $1,23.9 \pm 0.6 \mathrm{~g}(n=10)$; WT cohort 1 , $26.3 \pm 1.3 \mathrm{~g}(n=4) ;$ OXT-iCre $+3 D q$ cohort $2,28.9 \pm 1.3 \mathrm{~g}(n=$ 4); OXT-iCre (no 3Dq), $28.1 \pm 1.8 \mathrm{~g}(n=4)$; and WT cohort 2 , $30.4 \pm 1.6 \mathrm{~g}(n=4)$. Therefore, Nos $1^{\mathrm{PVH}}$ or $\mathrm{OXT}^{\mathrm{PVH}}$ neuron 
A

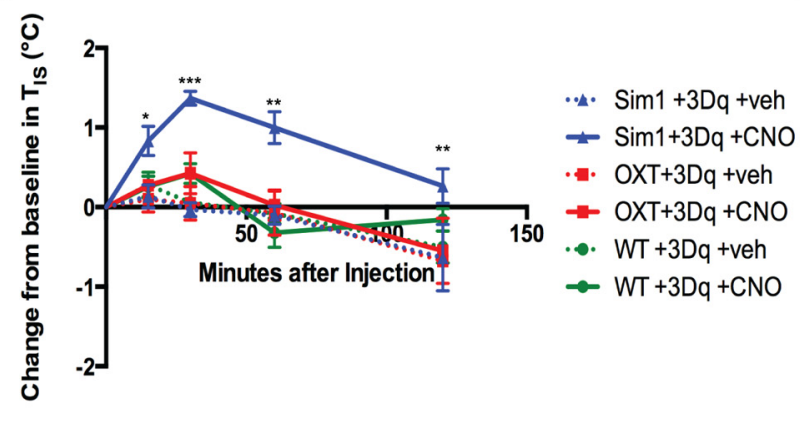

B

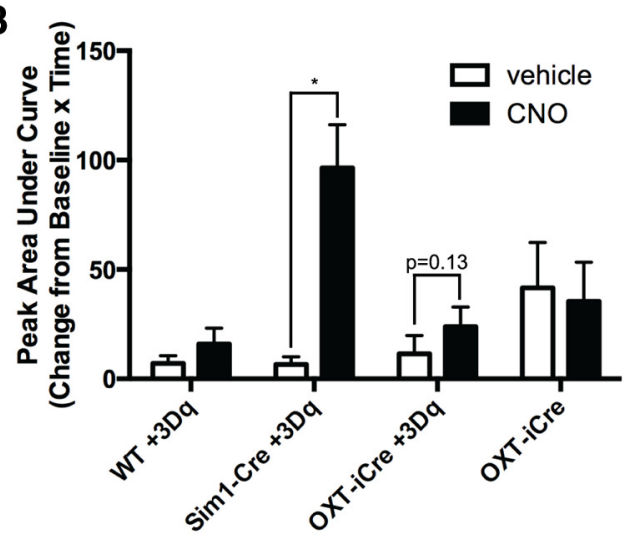

Figure 9. Acute activation of $\mathrm{Sim} 1^{\mathrm{PVH}}$ neurons increases subcutaneous intrascapular temperature. Sim 1-Cre $+3 D q, 0 X T-i C r e+3 D q$, and WT $+3 D$ q mice received temperature transponders in the subcutaneous intrascapular tissue directly above BAT. $\mathrm{T}_{\mathrm{IS}}$ was measured before and after vehicle or $\mathrm{CN} 0$ administration. $A, B, \mathrm{~T}_{\text {IS }}$ is shown relative to baseline $\mathrm{T}_{\text {IS }}$ before and after injection of vehicle or CNO ( $\boldsymbol{A}$, dashed and solid lines, respectively) and also is represented as the peak area under the curve $(\boldsymbol{B})$. Average values \pm SEM are shown. ${ }^{*} p<0.05,{ }^{* *} p<0.01,{ }^{* * *} p<0.001$ compared with vehicle values (WT, $n=5 ; \operatorname{Sim} 1$-Cre, $n=3 ;$ OXT-iCre, $n=4$ ). Significance was determined using repeated-measures two-way ANOVA with Sidak multiple-comparisons post hoc test.

activation promotes locomotor activity and overall energy expenditure, although to a lesser extent than that seen with pan$\mathrm{PVH}$ activation. Unlike the feeding effects observed with Nos $1^{\mathrm{PVH}}$ activation, Nos $1^{\mathrm{PVH}}$-driven increases in $\mathrm{VO}_{2}$ and activity were significantly smaller than those seen with $\mathrm{Sim} 1^{\mathrm{PVH}}$ activation (unpaired $t$ test of average $4 \mathrm{~h} \mathrm{VO}_{2}, F_{(3,3)}=1.062, p=$ 0.009; unpaired $t$ test of average 4 h activity, $F_{(3,3)}=274.3, p=$ $0.023)$, suggesting that both Nos $1^{\mathrm{PVH}}$ and non-Nos $1^{\mathrm{PVH}}$ subsets of Sim 1 neurons contribute to the control of energy expenditure. As increased locomotor activity may contribute to overall energy expenditure and $\mathrm{VO}_{2}$, we analyzed $\mathrm{VO}_{2}$ in Sim1-Cre+AAVhM3Dq and Nos1-iCre+AAV-hM3Dq mice at time points when locomotor activity was approximately matched before and after CNO treatment (Fig. $8 F$ ). While this analysis revealed a trend toward increased $\mathrm{VO}_{2}$ for both Sim1-Cre+AAV-hM3Dq and Nos1-iCre+AAV-hM3Dq animals when matched for activity (Sim1-Cre, paired $t$ test, $t_{(3)}=2.4, p=0.093$; Nos1-iCre, paired $t$ test, $\left.t_{(3)}=2.9, p=0.064\right)$, the magnitude of the effect was small relative to the overall increase in $\mathrm{VO}_{2}$. This suggests that increased locomotor activity contributes significantly to the increased oxygen consumption observed with PVH stimulation, but that changes independent of locomotor activity may also play a role.

\section{Acute Sim $1^{\mathrm{PVH}}$ activation increases intrascapular BAT temperature}

Since the activation of PVH neurons tends to increase energy expenditure in mice matched for locomotor activity, and $\mathrm{Sim}_{1}{ }^{\mathrm{PVH}}, \mathrm{Nos} 1^{\mathrm{PVH}}$, and $\mathrm{OXT} \mathrm{T}^{\mathrm{PVH}}$ neurons send dense projections to preganglionic sympathetic ChAT neurons in the thoracic spinal cord, we hypothesized that activation of these PVH subpopulations might promote thermogenesis in addition to potentially playing a role in locomotor activation. To test this, temperature transponders were placed in the subcutaneous tissue directly above intrascapular BAT in Sim1-Cre+AAV+hM3Dq, $\mathrm{OXT}-\mathrm{iCre}+\mathrm{AAV}+\mathrm{hM} 3 \mathrm{Dq}$, and $W T+\mathrm{AAV}+\mathrm{hM} 3 \mathrm{Dq}$ mice and intrascapular temperatures $\left(\mathrm{T}_{\mathrm{IS}} \mathrm{s}\right)$ were measured before and after PVH neuron activation. Body weights $( \pm$ SEM) of the animals used in these studies are as follows: Sim1-Cre, $27.4 \pm 1.6 \mathrm{~g}(n=$ 3); OXT-iCre, $28.5 \pm 0.8 \mathrm{~g}(n=4)$; and WT, $31.5 \pm 1.2 \mathrm{~g}(n=5)$. Activation of $\operatorname{Sim} 1^{\mathrm{PVH}}$ neurons increased $\mathrm{T}_{\mathrm{IS}} \mathrm{S}$ when compared with baseline $\mathrm{T}_{\mathrm{IS}}$ s before injection of vehicle or $\mathrm{CNO}$ (Fig. 9A, $B$; repeated-measures two-way ANOVA of change in baseline $\mathrm{T}_{I S} \mathrm{~S}$,
$F_{(1,2)}=102.9, p=0.010$ with Sidak multiple-comparisons post hoc test: $15 \mathrm{~min}, t_{(8)}=4.2, p=0.016 ; 30 \mathrm{~min}, t_{(8)}=8.3, p<0.001$; $\left.60 \mathrm{~min}, t_{(8)}=6.5, p=0.001 ; 120 \mathrm{~min}, t_{(8)}=5.3, p=0.004\right)$. Additionally, activation of $\mathrm{OXT}^{\mathrm{PVH}}$ neurons display a trend of increased $\mathrm{T}_{\mathrm{IS}}$, though this did not reach statistical significance. $\mathrm{T}_{\mathrm{IS}}$ in $\mathrm{WT}+\mathrm{AAV}+\mathrm{hM} 3 \mathrm{Dq}$ mice were not altered in response to CNO administration.

Since acute PVH activation increased $\mathrm{T}_{\mathrm{IS}}$, we determined whether this was mediated by increased BAT uncoupling protein 1 (UCP1), the primary facilitator of BAT thermogenesis (Matthias et al., 2000). We examined UCP1 protein levels in BAT from Sim1-Cre+AAV-hM3Dq, OXT-iCre+AAV-hM3Dq, or WT+AAVhM3Dq mice treated with either vehicle or CNO. UCP1 protein levels did not change in response to $\mathrm{Sim} 1^{\mathrm{PVH}}$ or $\mathrm{OXT}^{\mathrm{PVH}}$ neuronal activation when normalized to the loading control (Fig. 10). Therefore, increases in $\mathrm{T}_{\text {IS }}$ following $\mathrm{PVH}$ activation may be due to mechanisms that increase UCP1 activity rather than protein levels (Divakaruni et al., 2012; Richard et al., 2012).

\section{Discussion}

The importance of the PVH in feeding regulation, energy balance, and endocrine and autonomic function is well established (Sawchenko and Swanson, 1982; Cowley et al., 1999; Balthasar et al., 2005). However, a detailed understanding of the cellular and neural pathways used by the PVH to regulate these physiologic functions has been complicated by the heterogeneity of this nucleus and the inability to investigate specific $\mathrm{PVH}$ cell populations independently. To tackle these issues, we combined Credependent viral vectors with $\mathrm{PVH}$ cell-specific Cre drivers to probe the function of discrete PVH neuron subsets and explore their connectivity with brain regions known to be involved in energy homeostasis.

The hypothalamic transcription factor Sim1 marks PVH neurons involved in feeding regulation. Sim1-restricted melanocortin-4 receptor (Mc4R) expression in an otherwise Mc4R-null background corrects the associated hyperphagia of Mc4R-null mice and targeted ablation of Siml neurons in the CNS results in hyperphagia and altered energy expenditure (Balthasar et al., 2005; Xi et al., 2012). Sim1 neurons lie in other brain areas, but most if not all PVH neurons express Sim1 (Michaud et al., 1998). We now show that acute activation of $\operatorname{Sim} 1^{\mathrm{PVH}}$ neurons suppresses feeding and increases energy expenditure and activity, highlighting the ability of PVH neurons to 
A
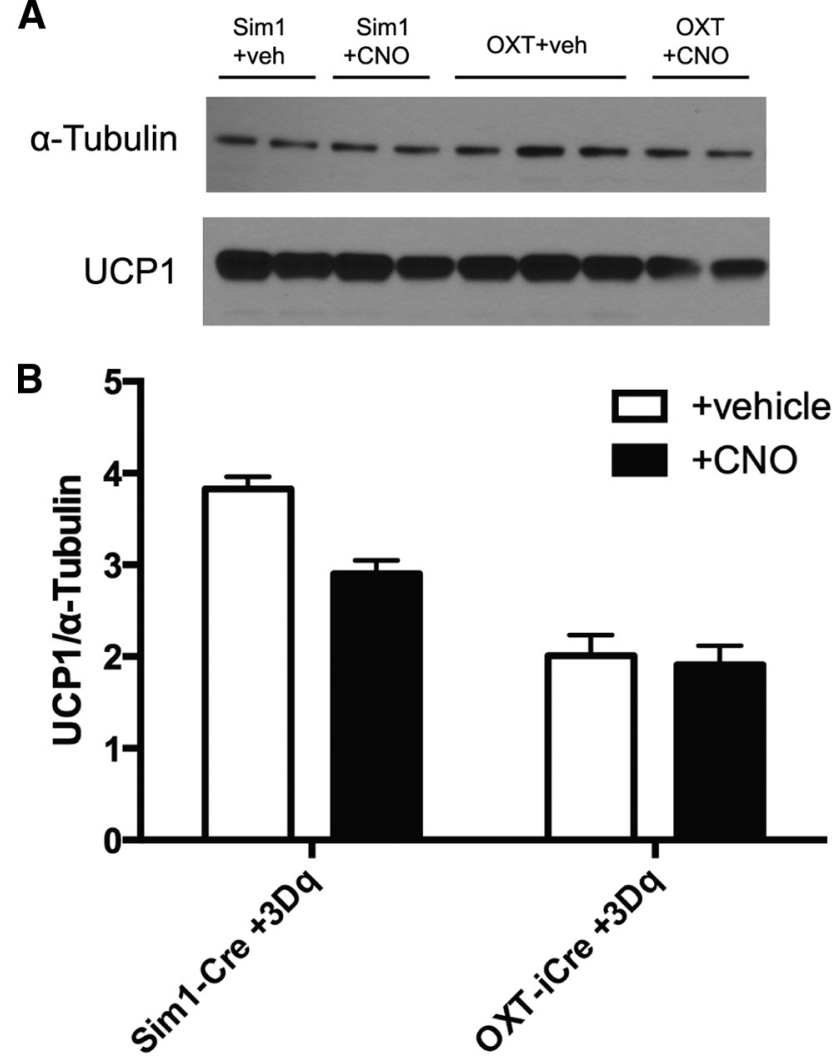

Figure 10. Acute activation of PVH neurons does not alter BAT UCP1 protein expression. BAT protein lysates were prepared from Sim 1-Cre +3Dq and OXT-iCre + 3Dq mice treated with either vehicle or $\mathrm{CNO}$ for $90 \mathrm{~min}$. $A, \mathrm{UCP} 1$ protein levels are no different following $\mathrm{Sim}^{1}{ }^{\mathrm{PVH}}$ (left) or $\mathrm{OXT}^{\mathrm{PVH}}$ (right) activation with CNO compared with vehicle. B, Quantification of BAT UCP1 protein levels relative to the loading control, $\alpha$-tubulin [Sim1 + vehicle (veh), $n=2 ; \operatorname{Sim} 1+$ CN0, $n=2 ; 0 \mathrm{XT}+\mathrm{veh}, n=3 ;$ OXT + CNO,$n=2]$.

regulate both energy balance parameters and validating our experimental system. To clarify the neurochemical identity and neural circuitry of the PVH neurons mediating these effects, we identified and used Nos1 expression to mark a specific Sim $1^{\mathrm{PVH}}$ subset. Our tracing studies revealed dense Nos1 ${ }^{\mathrm{PVH}}$ projections to hindbrain and spinal cord structures involved in energy balance regulation. Using a pharmacogenetic approach, we showed that activation of Nos $1^{\mathrm{PVH}}$ neurons suppressed food intake at the onset of feeding to an extent that is comparable to that observed upon activation of the entire Sim $1^{\mathrm{PVH}}$ field. These experiments therefore establish Nos $1^{\mathrm{PVH}}$ neurons as an important Sim $1^{\mathrm{PVH}}$ subset in feeding regulation.

$\mathrm{OXT}^{\mathrm{PVH}}$ neurons are a subset of Nos1 ${ }^{\mathrm{PVH}}$ neurons and pharmacologic evidence has demonstrated the ability of hindbrain OXT action to suppress feeding, suggesting a role for $\mathrm{OXT}^{\mathrm{PVH}}$ neurons in anorectic signaling by the PVH (Blevins et al., 2004; Kublaoui et al., 2008; Tolson et al., 2010). In contrast, however, genetic inactivation of OXT or its receptors minimally impacts feeding, and ablation of OXT neurons in adult mice neither alters feeding nor the anorexic response to a melanocortin agonist (Takayanagi et al., 2008; Camerino, 2009; Wu et al., 2012). To determine the contribution of $\mathrm{OXT}^{\mathrm{PVH}}$ neurons to $\mathrm{Nos}^{\mathrm{PVH}}{ }^{\mathrm{PV}}$-regulated feeding, we subjected $\mathrm{OXT}^{\mathrm{PVH}}$ neurons to Cre-dependent synaptic tracing and pharmacogenetic analysis. DREADD-mediated activation of $\mathrm{OXT}^{\mathrm{PVH}}$ neurons failed to suppress feeding under normal conditions. Therefore, while Nos1 ${ }^{\mathrm{PVH}}$ neurons mediate a powerful anorectic signal, the OXT-expressing subset of Nos $1^{\mathrm{PVH}}$ neurons cannot account for this effect, thus revealing a requisite role for non-OXT Nos1 ${ }^{\mathrm{PVH}}$ neurons in food intake control.

The role of the PVH in energy expenditure regulation has received less attention than its role in food intake control. Sim1 haploinsufficiency or manipulation of Mc4R expression in Sim1 neurons alters feeding, but minimally affects energy expenditure (Michaud et al., 2001; Balthasar et al., 2005). Selective ablation of Sim 1 neurons in the CNS, however, lowers oxygen consumption, suggesting a role for Sim 1 neurons in the regulation of both food intake and energy expenditure (Xi et al., 2012). Indeed, recent data reveal that glutamatergic signaling in Sim 1 neurons contributes to energy expenditure regulation (Xu et al., 2013). In this study, we show that direct activation of $\operatorname{Sim} 1^{\mathrm{PVH}}$ neurons increases energy expenditure, and that both $\mathrm{Nos}^{\mathrm{PVH}}$ and $\mathrm{OXT}^{\mathrm{PVH}}$ neurons contribute to this physiologic response. Using a novel anterograde viral tracing tool, we did not find significant projections to the RPa. However, we did identify dense terminals from $\mathrm{Sim}_{1}^{\mathrm{PVH}}$, Nos $1^{\mathrm{PVH}}$, and $\mathrm{OXT}^{\mathrm{PVH}}$ neurons in close proximity to $\mathrm{ChAT}^{\mathrm{IML}}$ neurons of the thoracic spinal cord, a cholinergic preganglionic structure that regulates sympathetic output. Importantly, direct activation of Nos1 ${ }^{\mathrm{PVH}}$ and $\mathrm{OXT}^{\mathrm{PVH}}$ neurons appears to stimulate $\mathrm{ChAT}^{\mathrm{IML}}$ cells concomitant with increases in metabolic rate, locomotor activity, and thermogenesis. This physical connection between PVH neuron subsets and ChAT ${ }^{\mathrm{IML}}$ neurons provides a potential neuroanatomical mechanism by which sympathetic output may be increased to promote energy expenditure following activation of these $\mathrm{PVH}$ neurons. Indeed, activation of Sim ${ }^{\mathrm{PVH}}$ neurons increases intrascapular temperature overlying BAT. As thermogenesis requires BAT UCP1 (Cannon and Nedergaard, 2004), and there is no change in UCP1 protein expression following Sim $1^{\mathrm{PVH}}$ stimulation, this effect is likely dependent on a change in UCP1 activity.

The increase in oxygen consumption upon Sim $1^{\mathrm{PVH}}$ activation is more robust than that seen with activation of either $\operatorname{Nos}_{1}^{\mathrm{PVH}}$ or $\mathrm{OXT}^{\mathrm{PVH}}$ neurons alone. Interestingly, the extent of $\mathrm{ChAT}^{\mathrm{IML}}$ activation is relatively similar, suggesting that additional CNS pathways are engaged to regulate energy expenditure acutely. Only an estimated 25\% of hindbrain and spinal cordprojecting PVH neurons have been neurochemically defined (Sawchenko and Swanson, 1982). Therefore, other, unidentified PVH neurons likely play important roles in modulating energy expenditure. Additional studies directed at identifying and manipulating chemically defined populations of PVH neurons will be critical in understanding the cellular and neuroanatomical pathways used by the PVH to modulate energy expenditure and achieve energy homeostasis.

The neurotransmitters by which $\mathrm{Nos}^{\mathrm{PVH}}$ and $\mathrm{OXT}^{\mathrm{PVH}}$ neurons regulate feeding and energy expenditure remain undefined. It is likely that both neuropeptides and fast-acting neurotransmitters such as glutamate, the predominant PVH neurotransmitter, contribute to PVH-mediated energy balance. Indeed, Sim1 glutamate signaling is important for overall control of energy balance (Xu et al., 2013). Our DREADD activation studies suggest the possibility that PVH neurons regulate adjacent cells. Given the presence of local, intra-PVH glutamatergic connections, it is conceivable that $\mathrm{PVH}$ neuronal subsets can recruit certain neighboring cell types to affect functional outputs (Ziegler and Herman, 2000).

Overall, our dissection of PVH neuron subpopulations reveals that specific subsets of PVH neurons play distinct roles in energy balance regulation. Specifically, we reveal a role for $\mathrm{Nos}_{1}{ }^{\mathrm{PVH}}$ neurons in the control of feeding, and that this function requires the participation of non-OXT Nos1 ${ }^{\mathrm{PVH}}$ neurons. Moreover, both 
Nos $1^{\mathrm{PVH}}$ and the $\mathrm{OXT} \mathrm{T}^{\mathrm{PVH}}$ neurons project to sympathetic output areas of the thoracic spinal cord and are capable of increasing energy expenditure (although to a lesser extent than Sim1 $1^{\mathrm{PVH}}$ neurons, suggesting roles for non-Nos $1 \mathrm{Sim} 1^{\mathrm{PVH}}$ cells). The identification and analysis of other PVH subpopulations will be crucial to determining the molecular mechanisms by which the PVH regulates energy homeostasis.

\section{References}

Alexander GM, Rogan SC, Abbas AI, Armbruster BN, Pei Y, Allen JA, Nonneman RJ, Hartmann J, Moy SS, Nicolelis MA, McNamara JO, Roth BL (2009) Remote control of neuronal activity in transgenic mice expressing evolved G protein-coupled receptors. Neuron 63:27-39. CrossRef Medline

Balthasar N, Dalgaard LT, Lee CE, Yu J, Funahashi H, Williams T, Ferreira M, Tang V, McGovern RA, Kenny CD, Christiansen LM, Edelstein E, Choi B, Boss O, Aschkenasi C, Zhang CY, Mountjoy K, Kishi T, Elmquist JK, Lowell BB (2005) Divergence of melanocortin pathways in the control of food intake and energy expenditure. Cell 123:493-505. CrossRef Medline

Bamshad M, Song CK, Bartness TJ (1999) CNS origins of the sympathetic nervous system outflow to brown adipose tissue. Am J Physiol 276: R1569-R1578. Medline

Bergner AJ, Stamp LA, Gonsalvez DG, Allison MB, Olson DP, Myers MG, Myers MG Jr, Anderson CR, Young HM (2014) Birthdating of myenteric neuron subtypes in the small intestine of the mouse. J Comp Neurol 522:514-527. CrossRef Medline

Blevins JE, Schwartz MW, Baskin DG (2004) Evidence that paraventricular nucleus oxytocin neurons link hypothalamic leptin action to caudal brain stem nuclei controlling meal size. Am J Physiol Regul Integr Comp Physiol 287:R87-R96. CrossRef Medline

Boudaba C, Szabó K, Tasker JG (1996) Physiological mapping of local inhibitory inputs to the hypothalamic paraventricular nucleus. J Neurosci 16:7151-7160. Medline

Camerino C (2009) Low sympathetic tone and obese phenotype in oxytocin-deficient mice. Obesity (Silver Spring) 17:980-984. CrossRef Medline

Cannon B, Nedergaard J (2004) Brown adipose tissue: function and physiological significance. Physiol Rev 84:277-359. CrossRef Medline

Cano G, Passerin AM, Schiltz JC, Card JP, Morrison SF, Sved AF (2003) Anatomical substrates for the central control of sympathetic outflow to interscapular adipose tissue during cold exposure. J Comp Neurol 460: 303-326. CrossRef Medline

Cowley MA, Pronchuk N, Fan W, Dinulescu DM, Colmers WF, Cone RD (1999) Integration of NPY, AGRP, and melanocortin signals in the hypothalamic paraventricular nucleus: evidence of a cellular basis for the adipostat. Neuron 24:155-163. CrossRef Medline

Divakaruni AS, Humphrey DM, Brand MD (2012) Fatty acids change the conformation of uncoupling protein 1 (UCP1). J Biol Chem 287:3684536853. CrossRef Medline

Fulwiler CE, Saper CB (1985) Cholecystokinin-immunoreactive innervation of the ventromedial hypothalamus in the rat: possible substrate for autonomic regulation of feeding. Neurosci Lett 53:289-296. CrossRef Medline

Gold RM (1973) Hypothalamic obesity: the myth of the ventromedial nucleus. Science 182:488-490. CrossRef Medline

Herbison AE, Simonian SX, Norris PJ, Emson PC (1996) Relationship of neuronal nitric oxide synthase immunoreactivity to GnRH neurons in the ovariectomized and intact female rat. J Neuroendocrinol 8:73-82. CrossRef Medline

Holder JL Jr, Butte NF, Zinn AR (2000) Profound obesity associated with a balanced translocation that disrupts the SIM1 gene. Hum Mol Genet 9:101-108. CrossRef Medline

Kishi T, Aschkenasi CJ, Lee CE, Mountjoy KG, Saper CB, Elmquist JK (2003) Expression of melanocortin 4 receptor mRNA in the central nervous system of the rat. J Comp Neurol 457:213-235. CrossRef Medline
Kublaoui BM, Gemelli T, Tolson KP, Wang Y, Zinn AR (2008) Oxytocin deficiency mediates hyperphagic obesity of $\operatorname{Sim} 1$ haploinsufficient mice. Mol Endocrinol 22:1723-1734. CrossRef Medline

Leshan RL, Greenwald-Yarnell M, Patterson CM, Gonzalez IE, Myers MG Jr (2012) Leptin action through hypothalamic nitric oxide synthase-1expressing neurons controls energy balance. Nat Med 18:820-823. CrossRef Medline

Matthias A, Ohlson KB, Fredriksson JM, Jacobsson A, Nedergaard J, Cannon B (2000) Thermogenic responses in brown fat cells are fully UCP1dependent. UCP2 or UCP3 do not substitute for UCP1 in adrenergically or fatty scid-induced thermogenesis. J Biol Chem 275:25073-25081. CrossRef Medline

McKinley MJ, Johnson AK (2004) The physiological regulation of thirst and fluid intake. News Physiol Sci 19:1-6. CrossRef Medline

Michaud JL, Boucher F, Melnyk A, Gauthier F, Goshu E, Lévy E, Mitchell GA, Himms-Hagen J, Fan CM (2001) Siml haploinsufficiency causes hyperphagia, obesity and reduction of the paraventricular nucleus of the hypothalamus. Hum Mol Genet 10:1465-1473. CrossRef Medline

Michaud JL, Rosenquist T, May NR, Fan CM (1998) Development of neuroendocrine lineages requires the bHLH-PAS transcription factor SIM1. Genes Dev 12:3264-3275. CrossRef Medline

Morrison SF (1999) RVLM and raphe differentially regulate sympathetic outflows to splanchnic and brown adipose tissue. Am J Physiol 276:R962R973. Medline

Münzberg H, Jobst EE, Bates SH, Jones J, Villanueva E, Leshan R, Björnholm M, Elmquist J, Sleeman M, Cowley MA, Myers MG Jr (2007) Appropriate inhibition of orexigenic hypothalamic arcuate nucleus neurons independently of leptin receptor/STAT3 signaling. J Neurosci 27:69-74. CrossRef Medline

Opland D, Sutton A, Woodworth H, Brown J, Bugescu R, Garcia A, Christensen L, Rhodes C, Myers M Jr, Leinninger G (2013) Loss of neurotensin receptor-1 disrupts the control of the mesolimbic dopamine system by leptin and promotes hedonic feeding and obesity. Mol Metab 2:423-434. CrossRef Medline

Paxinos G, Franklin K (2001) The mouse brain in stereotaxic coordinates Ed 2. San Diego: Academic.

Richard D, Monge-Roffarello B, Chechi K, Labbé SM, Turcotte EE (2012) Control and physiological determinants of sympathetically mediated brown adipose tissue thermogenesis. Front Endocrinol (Lausanne) 3:36. CrossRef Medline

Sawchenko PE, Swanson LW (1982) The organization of noradrenergic pathways from the brainstem to the paraventricular and supraoptic nuclei in the rat. Brain Res 257:275-325. Medline

Sims JS, Lorden JF (1986) Effect of paraventricular nucleus lesions on body weight, food intake and insulin levels. Behav Brain Res 22:265-281. CrossRef Medline

Takayanagi Y, Kasahara Y, Onaka T, Takahashi N, Kawada T, Nishimori K (2008) Oxytocin receptor-deficient mice developed late-onset obesity. Neuroreport 19:951-955. CrossRef Medline

Tolson KP, Gemelli T, Gautron L, Elmquist JK, Zinn AR, Kublaoui BM (2010) Postnatal Siml deficiency causes hyperphagic obesity and reduced Mc4r and oxytocin expression. J Neurosci 30:3803-3812. CrossRef Medline

Wu Z, Xu Y, Zhu Y, Sutton AK, Zhao R, Lowell BB, Olson DP, Tong Q (2012) An obligate role of oxytocin neurons in diet induced energy expenditure. PLoS One 7:e45167. CrossRef Medline

Xi D, Gandhi N, Lai M, Kublaoui BM (2012) Ablation of Sim1 neurons causes obesity through hyperphagia and reduced energy expenditure. PLoS One 7:e36453. CrossRef Medline

Xu Y, Wu Z, Sun H, Zhu Y, Kim ER, Lowell BB, Arenkiel BR, Xu Y, Tong Q (2013) Glutamate mediates the function of melanocortin receptor 4 on sim1 neurons in body weight regulation. Cell Metab 18:860-870. CrossRef Medline

Ziegler DR, Herman JP (2000) Local integration of glutamate signaling in the hypothalamic paraventricular region: regulation of glucocorticoid stress responses. 141:4801-4804 